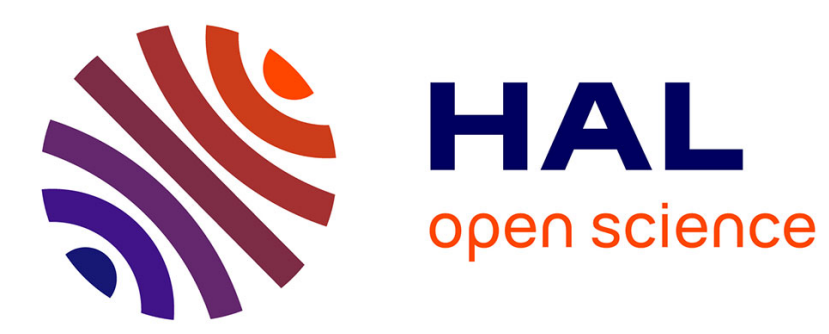

\title{
MARSIS radar sounder observations in the vicinity of Ma'adim Vallis, Mars
}

Oliver L. White, Ali Safaeinili, Jeffrey J. Plaut, Ellen R. Stofan, Stephen M. Clifford, William M. Farrell, Essam Heggy, Giovanni Picardi

\section{To cite this version:}

Oliver L. White, Ali Safaeinili, Jeffrey J. Plaut, Ellen R. Stofan, Stephen M. Clifford, et al.. MARSIS radar sounder observations in the vicinity of Ma'adim Vallis, Mars. Icarus, 2009, 201 (2), pp.460. 10.1016/j.icarus.2009.01.015 . hal-00533500

\section{HAL Id: hal-00533500 https://hal.science/hal-00533500}

Submitted on 7 Nov 2010

HAL is a multi-disciplinary open access archive for the deposit and dissemination of scientific research documents, whether they are published or not. The documents may come from teaching and research institutions in France or abroad, or from public or private research centers.
L'archive ouverte pluridisciplinaire HAL, est destinée au dépôt et à la diffusion de documents scientifiques de niveau recherche, publiés ou non, émanant des établissements d'enseignement et de recherche français ou étrangers, des laboratoires publics ou privés. 


\section{Accepted Manuscript}

MARSIS radar sounder observations in the vicinity of Ma'adim Vallis, Mars

Oliver L. White, Ali Safaeinili, Jeffrey J. Plaut, Ellen R. Stofan, Stephen M. Clifford, William M. Farrell, Essam Heggy, Giovanni Picardi

PII: $\quad$ S0019-1035(09)00034-7

DOI: $\quad$ 10.1016/j.icarus.2009.01.015

Reference: $\quad$ YICAR 8894

To appear in: Icarus

Received date: 4 December 2008

Revised date: 23 January 2009

Accepted date: 27 January 2009

Please cite this article as: O.L. White, A. Safaeinili, J.J. Plaut, E.R. Stofan, S.M. Clifford, W.M. Farrell, E. Heggy, G. Picardi, MARSIS radar sounder observations in the vicinity of Ma'adim Vallis, Mars, Icarus (2009), doi: 10.1016/j.icarus.2009.01.015

This is a PDF file of an unedited manuscript that has been accepted for publication. As a service to our customers we are providing this early version of the manuscript. The manuscript will undergo copyediting, typesetting, and review of the resulting proof before it is published in its final form. Please note that during the production process errors may be discovered which could affect the content, and all legal disclaimers that apply to the journal pertain. 


\section{MARSIS radar sounder observations in the vicinity of Ma'adim Vallis, Mars}

Oliver L. White ${ }^{1 *}$, Ali Safaeinili ${ }^{2}$, Jeffrey J. Plaut ${ }^{2}$, Ellen R. Stofan ${ }^{1,3}$, Stephen M. Clifford ${ }^{4}$, William M. Farrell ${ }^{5}$, Essam Heggy $^{2}$, Giovanni Picardi ${ }^{6}$, the MARSIS Science Team.

${ }^{1}$ UCL/Birkbeck Research School of Earth Sciences, Gower Street, London, WC1E 6BT, UK.

${ }^{2}$ Jet Propulsion Laboratory, California Institute of Technology, Pasadena, California, 91109, USA.

${ }^{3}$ Proxemy Research, Laytonsville, Maryland, 20882, USA.

${ }^{4}$ Lunar and Planetary Institute, Houston, Texas, 77058, USA.

${ }^{5}$ NASA/Goddard Space Flight Center, Greenbelt, Maryland, 20771, USA.

${ }^{6}$ Infocom Department, "La Sapienza” University of Rome, 00184, Rome, Italy.

Manuscript pages: 34

Figures: 8

Tables: 3 
Running head: MARSIS radar observations over Ma'adim Vallis, Mars

Address editorial correspondence and proofs to: Oliver White

Department of Earth Sciences

University College London

Gower Street

London

WC1E 6BT

o.white@ucl.ac.uk

Ali Safaeinili: ali.safaeinili@jpl.nasa.gov Jeffrey J. Plaut: plaut@mail.jpl.nasa.gov

Ellen R. Stofan: ellen@proxemy.com

Stephen M. Clifford: clifford@lpi.usra.edu

William M. Farrell: William.M.Farrell@nasa.gov

Essam Heggy: essam.heggy@jpl.nasa.gov

Giovanni Picardi: picar@infocom.uniroma1.it 


\begin{abstract}
The MARSIS radar experiment aboard the ESA Mars Express satellite has recorded several unusual reflections in the Ma'adim Vallis region of Mars. These reflections display a wide variety of morphologies which are very different from those of reflections seen beneath the Polar Layered Deposits, Medusae Fossae Formation and Dorsa Argentea Formation. Their morphologies are sometimes very laterally extensive, parabolic or hyperbolic, and apparently deep, but they can also appear horizontal and shallow. Aided by a geological map of the Ma'adim Vallis region, the morphological, locational and temporal characteristics of the reflections have been studied individually in an attempt to constrain their origin. While some may be subsurface reflections based on their shallow morphologies and correlation with the Eridania Planitia basin network, all of the reflections are ambiguous to some degree, displaying characteristics that do not allow a definite subsurface- or possibly ionospheric-sourced mechanism to be proposed for their creation. Those with more exaggerated morphologies are regarded as being much more likely to result from ionospheric distortion rather than subsurface inhomogeneity.
\end{abstract}

Keywords: Mars, radar observations, ionospheres 


\section{Introduction}

The MARSIS radar sounder aboard ESA's Mars Express satellite, which has been obtaining radar profiles of the Martian subsurface since June 2005, has detected the bases of the polar layered deposits (PLDs) (Plaut et al., 2007a), the Medusae Fossae Formation (MFF) (Watters et al., 2007), and a reflector beneath the Dorsa Argentea Formation that partially encircles the South Polar layered deposits (Plaut et al., 2007b). One of the few other locations on the planet where there are numerous reflections clustered in one location is the Ma'adim Vallis region, located just to the south of the dichotomy boundary at $\sim 180^{\circ}$ longitude. Ma'adim Vallis is one of the most prominent valleys in the Martian highlands with a width of 8 to $15 \mathrm{~km}$ and a length of $900 \mathrm{~km}$ (Irwin et al., 2002). A system of tributaries occurs at the head of the valley, which meanders northwards, terminating in the $150 \mathrm{~km}$ diameter Gusev impact crater, site of operations of the Mars Exploration Rover Spirit. It has been interpreted that water and aqueous sediments ponded here after being carried through the valley inlet in the southern rim of Gusev crater (Cabrol et al., 1996), and the results of the science investigations of Spirit to date have confirmed that aqueous infiltration, cementation and alteration have affected impact and volcaniclastic materials present at the site (McCoy et al., 2008).

The Ma'adim reflections were recorded between February 2006 and October 2008 and are more enigmatic than those seen beneath the PLD and MFF. Whereas the other two regions display reflections that are sharp, continuous, aligned parallel to the surface and consistent between adjacent radargrams, the Ma'adim reflections are more irregular in shape and distribution. We discuss the origin of these reflections using geological mapping of the area as well as the results of previous studies focusing on the Martian ionosphere. We hope to determine whether the reflections originate from subsurface dielectric interfaces or some 
other process related to ionospheric distortion based on their morphological, locational and temporal characteristics.

\section{Methods}

MARSIS is a multifrequency, synthetic-aperture, orbital sounding radar. Data are collected when the elliptical orbit of Mars Express brings the spacecraft to an altitude of 250 to $800 \mathrm{~km}$ above the surface. In its subsurface modes, MARSIS operates in four frequency bands between 1.3 and $5.5 \mathrm{MHz}$, with a $1-\mathrm{MHz}$ instantaneous bandwidth that provides freespace range resolution of approximately $150 \mathrm{~m}$. Lateral spatial resolution depends on surface roughness characteristics, but for most Mars surfaces, the cross-track footprint is 10 to $30 \mathrm{~km}$ and the along-track footprint, narrowed by onboard synthetic-aperture processing, is 5 to 10 $\mathrm{km}$. The signal-to-noise ratio for a typical Mars surface ranges from 30 to $50 \mathrm{~dB}$ (Picardi et al., 2005).

A portion of the radio waves transmitted by MARSIS are reflected when they encounter a boundary between materials of different dielectric constants, and are recorded by MARSIS and processed to create a 'radargram' showing echo intensity as a function of horizontal distance along-track and two-way travel time of the radio waves. To first order, the intensity of the echoes is dependent on the contrast in dielectric constant at the boundary between the two materials: a stronger contrast will produce a stronger echo.

In order to estimate the depth to a reflector, the velocity of the radio waves through the crust $\left(v_{r}\right)$ must be known. The formula for this parameter is as follows:

$$
v_{r}=\frac{c}{\sqrt{\varepsilon_{r}}}
$$


where $c$ is the velocity of light in a vacuum and $\varepsilon_{r}$ is the real dielectric constant of the medium through which the radio waves are traveling (Daniels, 2004). The latter parameter can be estimated by measuring the intensity and time delay of the subsurface reflection, which can be used to assess the attenuation due to dielectric losses in the material. In materials other than ice (including rock and permafrost), and especially for sounding frequencies above $2 \mathrm{MHz}$, allowance must also be made for volume scattering. Based on ground-penetrating radar studies in terrestrial Mars-analogue volcanic terrains, volume scattering may induce losses that reach $15 \%$ to $20 \%$ of the total attenuation (Heggy et al., 2006).

MARSIS transmits signals with a wide beam, meaning that echoes are often received from off-nadir surface reflectors. The off-nadir reflections will have greater time delays and appear to be below the nadir surface reflection, giving the impression that they are subsurface reflections. This must be taken into account when interpreting reflections seen in MARSIS radargrams.

A geological map of the Ma'adim Vallis region was created in order to assess the likelihood of individual reflections resulting from subsurface interfaces by comparing the positions of the reflections with the positions of mapped geological units. The map was produced through the study of individual Mars Orbital Camera and THEMIS images as well as MOLA altimetric data.

\section{Results}

Figure 1 displays eight radargrams in the Ma'adim Vallis region that show range-delayed reflections, as well as five nearby radargrams which do not show any apparent subsurface reflections, other than off-nadir reflections predicted by simulations. The radargrams are in a 
region that extends across only $3.2^{\circ}$ of longitude (about $200 \mathrm{~km}$ ). The radargrams are grouped according to their locations and the characteristics of their reflections (Figs. 1a, 1b, 1c and $1 \mathrm{~d}$, the latter featuring radargrams displaying no reflections). The form of these reflections varies considerably: reflections such as those in radargrams 4786 and 2676 (Fig. 1a) occur at small time delays relative to the surface, are roughly horizontal and relatively laterally inextensive. Those in radargrams 2687 (Fig. 1b) and 4775 (Fig. 1c) have steeper, parabolic morphologies, reach much greater time delays, and have greater lateral extents. Those in radargrams 4808 and 3024 (Fig. 1b) display almost hyperbolic morphologies, whereby the central region of the reflection dips down steeply and fades away, creating two separate 'arms'. Radargrams 6145 and 2665 (Fig. 1c) display reflections with high time delays, but which are tenuous and discontinuous, apparently resembling segments of parabolas. The groups in Figs. 1a, 1b and 1c are examined in sections 4.1, 4.2, and 4.3 respectively. In order to simplify the reference system for the radargrams, each radargram will be assigned a reference letter in place of the four digit MARSIS orbit number; these are shown in Table 1.

Each radargram was obtained in two of the four frequency bands available to MARSIS (the specific frequency bands differ between radargrams): in each of the eight radargrams the reflections are apparent in both frequency bands. The morphologies of the reflections are fairly similar between the radargrams of different frequencies. The resolution of the reflections often varies for different sounding frequencies as demonstrated in Fig. 2 for radargram $\mathrm{E}$. This may be caused by variation in the magnitude of volume scattering (radio signals with different wavelengths will be scattered by inhomogeneities of different scales) or ionospheric attenuation.

To date, four SHARAD radagrams have been obtained over the Ma'adim Vallis region, yet none have been obtained within the localized longitude range $\left(173.5^{\circ} \mathrm{E}\right.$ to $\left.177^{\circ} \mathrm{E}\right)$ which 
harbors all the MARSIS radargrams discussed in sections 4.1, 4.2 and 4.3. All were obtained within the time period of April to June 2008. The groundtracks of the SHARAD radargrams are located up to $165 \mathrm{~km}$ east of the reflections in the MARSIS radargrams $\mathrm{G}$ and $\mathrm{H}$. MARSIS radargrams in these areas do not show any reflections similar to those described in radargrams to the west of Ma'adim Vallis, and this absence also characterizes the SHARAD radargrams - the only reflections that are apparent represent surface clutter. No conclusions regarding the validity of the MARSIS reflections can therefore be drawn from the currently available SHARAD radargrams, and future SHARAD data that is obtained over the same area as the reflection-bearing MARSIS radargrams are required.

\subsection{Geology of the Ma'adim Vallis Region}

Fig. 3 shows the geological map of the Ma'adim Vallis region with the locations of the MARSIS reflections indicated. Short descriptions and interpretations of the various units are included in the legend.

Of particular relevance to the present study is the mottled, dissected plains material (unit p4), which occurs in large topographic depressions south of Ma'adim Vallis, and which noticeably coincides with reflections in MARSIS radargrams A and B (Fig. 1a). This unit often has a mottled albedo and sometimes softens the relief of underlying features such as craters and wrinkle ridges, presumably in the areas where unit $\mathrm{p} 4$ is thin. The unit has been eroded in places (particularly in the basin to the west) to produce fretted, flat-topped mesalike features, indicative of weakly consolidated material. The $\mathrm{p} 4$ unit is often bounded by the p2 unit, whose numerous channel networks terminate in the $\mathrm{p} 4$ unit. A previous estimate of the crater density in this unit suggests a late Noachian age of $>3.5$ to 3.7 Ga (Irwin et al., 2002). The system of overlapping and highly degraded basins that harbor the $\mathrm{p} 4$ unit form 
Eridania Planitia, previously described in Irwin et al. $(2002 ; 2004)$ as having been occupied by lakes in the late Noachian which overflowed at the northern rim to form Ma'adim Vallis. The valley networks of unit p2 located in the surrounding highlands would have been a major source of water for these lakes. A similar configuration of lacustrine basins bordered by channeled terrain has been identified in the area surrounding Hesperia Planum (Jones et al., 2007). Irwin et al. (2002) noted the unusual bowl-shaped floors of these depressions, which they suggested had resulted from deposition of sediment around the margins of impact basins filled with standing water. This contrasts with flat-floored, sediment-filled basins, where fluvial rather than lacustrine regimes transport sediment far into the interior of the basins. Irwin et al. (2002) also noted that shoreline morphologies are evident in several locations on the rims of these basins. The location of the p4 unit corresponds reasonably well to the location of the hypothesized lake system described in Irwin et al. (2002; 2004) (outlined by the thick dotted line in Fig. 3). Sediments of the valley floor material (unit v1) at the head of Ma'adim Vallis border the lacustrine sediments of unit p4 in Eridania Planitia, supporting the hypothesis of Irwin et al. $(2002 ; 2004)$ that Ma'adim Vallis was formed after overflow of the lake system into an impact basin to the north during the late Noachian.

This area has been mapped previously in separate maps created during the Viking era in the late 1970s. They include that of the Aeolis Quadrangle by Scott et al. (1978), the south easternmost point of which is at $180^{\circ} \mathrm{E}, 30^{\circ} \mathrm{S}$; the Eridania Quadrangle by De Hon (1977), the north easternmost point of which is at $180^{\circ} \mathrm{E}, 30^{\circ} \mathrm{S}$; the Memnonia Quadrangle by Mutch and Morris (1979), the south westernmost point of which is at $180^{\circ} \mathrm{E}, 30^{\circ} \mathrm{S}$; and the Phaethontis Quadrangle by Howard III (1979), the north westernmost point of which is at $180^{\circ} \mathrm{E}, 30^{\circ} \mathrm{S}$. These maps describe the bulk of the terrain around Ma'adim Vallis as either 'hilly and cratered material' or 'cratered plateau material', analogous to the rough plain material in Fig. 3. The maps also describe 'plains material' which sometimes (but not always) coincides with 
the ridged plains material in Fig. 3, particularly in the eastern half of the map. The western half of Eridania Planitia is mapped as 'plains material' in Scott et al. (1978) and De Hon (1977), although its central region is mapped as 'hilly and cratered material'. Mutch and Morris (1979) and Howard III (1979) mapped the eastern parts of Eridania Planitia as 'plains material' and 'dissected plateau material', the latter being analogous to the mottled, dissected plains material in Fig. 3. The knobby mesa material and valley floor material in Fig. 3 are mapped in virtually identical locations in the earlier maps. The maps do not feature an analogy for the channeled plains material in Fig. 3.

\section{Discussion}

\subsection{Radargrams 4786 (A) and 2676 (B)}

Radargrams A and B (Fig. 1a) display shallow, horizontal reflections that are located to the east and south of Ma'adim Vallis; their groundtracks overlap almost exactly in the area where their reflections are seen. Radargram B displays two well-defined reflections (the northern one $160 \mathrm{~km}$ long, the southern one $275 \mathrm{~km}$ long). Reflections are discernible in similar locations in radargram A, positioned only a few $\mathrm{km}$ to the east of radargram $\mathrm{B}$. The reflections in radargram B attain one-way time delays of $5.5 \mu \mathrm{s}$ and $6.6 \mu \mathrm{s}$ for the northern and southern reflections respectively, while the time delays of the corresponding reflections in radargram A are $12.8 \mu$ s and $4.6 \mu$ s respectively. The time delays of the southern pair of reflections are similar, yet the time delays of the northern pair differ by a factor of more than two.

The southern reflections in radargrams $\mathrm{A}$ and $\mathrm{B}$ are notable in that the locations of their groundtracks correspond well to the boundaries of unit p4 mapped in Fig. 3. The reflections 
in both radargrams commence at the northern boundary of unit p4 (at the rim of Eridania Planitia). The A reflection commences at a 'step' representing the drop in topography at the boundary between Eridania Planitia and the cratered highlands. This step is not as apparent in B. The B reflection extends $\sim 50 \mathrm{~km}$ further to the north and south than the A reflection. The fact that these reflections nearly overlap and display similar, low time delays supports the interpretation that both of these reflections are caused by a subsurface interface comprising the base of deposits filling the Eridania Planitia basin. The reflections have a consistently high intensity suggestive of a pronounced dielectric contrast. However, the subsurface hypothesis does not account for the significant discrepancy in their lengths, unexpected given that they nearly overlap.

The northern reflections in the two radargrams do not appear to correspond to the surface geology when plotted on the map in Fig. 3, and do not seem to manifest themselves in adjacent radargrams (e.g. $\mathrm{M}$ and $\mathrm{K}$ in Fig. 1d). The possibility that the reflections are representative of a buried former course of Ma'adim Vallis was considered, yet detailed study of images in this vicinity revealed only cratered plains and no manifestation of any relict channels. A possible alternative is that the reflections may be off-nadir surface clutter. Figures $4 \mathrm{a}$ and $4 \mathrm{c}$ show ground-range projections of the reflections in radargrams $\mathrm{B}$ and $\mathrm{A}$ respectively, which plot where the reflections would fall on the surface (on both sides of the spacecraft groundtrack) if they were being produced by off-nadir surface clutter. Figures $4 \mathrm{~b}$ and $4 \mathrm{~d}$ compare the observed radargrams with simulations that model where reflections from off-nadir reflectors would be expected in the radargrams. Figures $4 \mathrm{a}$ and $4 \mathrm{c}$ show that the northern projections in both radargrams are aligned well with Ma'adim Vallis, yet are often offset from the channel typically by several tens of kilometers, although the southern segments of the northern B projection do coincide well with the wall of the channel. The southern projections in both radargrams do not coincide with any topographic features. 
Figures $4 \mathrm{~b}$ and $4 \mathrm{~d}$ show that the simulations do not predict any of the reflections seen in radargrams $\mathrm{A}$ and $\mathrm{B}$, although they do predict faint reflections originating from Ma'adim Vallis, which are seen in the observed data (highlighted by arrows).

Both sets of reflections (north and south) therefore either stem from a subsurface interface or are the product of ionospheric distortion. It is possible that they have different causes. In the case of the southern reflections, a potential subsurface interface could comprise the base of the Eridania Planitia lacustrine deposits (unit p4 in Fig. 3). For the northern reflections, the potential subsurface interface has no apparent surface expression. However, geological materials such as ice or high porosity rock are required to explain the strong dielectric contrast implied by the high intensity reflections. Using Eq. 1 and assuming a value of 5 for $\varepsilon_{r}$ of the surface layer (corresponding to the fluvial sediments in the second geoelectrical model of Heggy et al. (2003)), as well as accounting for volume scattering, the time delays of the reflections in radargram B would correspond to depths of $590 \mathrm{~m}$ and $710 \mathrm{~m}$ for the northern and southern reflections respectively, while the depths of the corresponding reflections in radargram A would be $1380 \mathrm{~m}$ and $500 \mathrm{~m}$ respectively. The lower value of $\varepsilon_{r}$ associated with an icy or porous rock (in the region of 3 to 5 (Zhang et al., 2008)) would result in greater inferred depths of these reflections if either or both of these properties characterized the surface layer. The strongest evidence against a subsurface origin is that the reflections are not manifested in adjacent radargrams such as $\mathrm{K}$ to the west and $\mathrm{G}$ and $\mathrm{M}$ to the east (Figs. 1c, d), unexpected given the consistently high definition of the reflections within their radargrams as well as their substantial lateral extents. The fact that the timedelay of the northern reflection differs significantly between the two radargrams, whose groundtracks overlap at this point, suggests that ionospheric interference may have influenced the paths of the MARSIS signals differently at the times the radargrams were recorded - the potential for this occurring will be discussed in section 4.4 . 
Radargram B also displays two additional, tenuous reflections at its southern end that have higher time delays than the aforementioned reflections; these reflections are horizontal at their northern ends, yet dip as they progress to the south, and are not predicted by the simulation in Fig. 4b. Figure 4a shows that these reflections do not correspond to any offnadir topography, in which case they may alternatively be explained by ionospheric distortion of MARSIS signals.

Radargram L (Fig. 1d), whose groundtrack coincides almost exactly with those of A and B, was obtained on the dayside and appears to have been affected by the increased electron density in the dayside ionosphere. As such, the surface reflection seen in this radargram is considerably blurred; possible manifestations of subsurface reflections are seen in the same locations as those seen in radargrams A and B, yet they are too distorted and tenuous to confirm as being definitely related to those in the other radargrams.

\subsection{Radargrams 4808 (C), 3024 (D), and 2687 (E)}

The reflections in radargrams C, D and E (Fig. 1b) are quite different from those already considered. They (along with those in radargrams F, G and H in Fig. 1c) tend to have much greater lateral extents, reach greater time delays, and dip at greater angles than the other relatively flat reflections. They appear to have little or no relation to the surface geomorphology.

Radargram E displays a reflection that is very long $(\sim 790 \mathrm{~km})$, with shallow, gentlydipping outer margins (each 175-220 km long, reaching a one-way time delay of $9.4 \mu \mathrm{s}$ ) that dip sharply as they approach the center. The southern half of the reflection flattens out at the center and appears to undercut the northern reflection. The reflection has a maximum one- 
way time delay of $33.9 \mu \mathrm{s}$. Compared to the other reflections in this group, the E reflection has a consistently sharp definition.

The location of this reflection roughly corresponds to a circular region of slightly lower topography than its surroundings, one of the subtle 'quasi-circular depressions' (QCDs) described by Frey et al. (2002). The QCD in question has a diameter of $\sim 400 \mathrm{~km}$, is bisected by Ma'adim Vallis and is interpreted to be an ancient, eroded impact basin (Irwin et al., 2002). A possible origin for this reflection is that it represents the basal contact between the basin-fill of the QCD and the substrate. If so, the deepest part of the reflection would represent a thickness of the basin-fill of $4.5 \mathrm{~km}$ (assuming a value of 5 for $\varepsilon_{r}$ ). This would, however, contrast with the estimate of MARSIS penetration in a lithic environment obtained by Heggy et al. (2006), who suggested an average penetration depth of 500 meters based on ground-penetrating radar surveys of an eroded Mars-analogue lava flow at Craters of the Moon volcanic field, Idaho. The surface layer would need to be comprised of an implausibly low-attenuation material to result in such a strong return from such a high time delay.

Alternatively, rather than being a nadir reflection from the curved, buried floor of the impact basin, the reflection may be an off-nadir echo from the buried rim of the impact basin, produced via the same mechanism suggested by Watters et al. (2006) and Picardi et al. (2005) to explain the parabolic reflections seen by MARSIS in the northern plains (see Fig. 4 in Picardi et al. (2005)).

Figure 5a shows the ground-range projection of the E reflection, indicating the extent to which the reflection and QCD basin rim overlap. The lateral extent of the reflection is actually larger than the width of the QCD along the orbit groundtrack, and the centers of the two features are offset by more than $\sim 220 \mathrm{~km}$, thus making both of the aforementioned hypotheses somewhat doubtful. Figure $5 \mathrm{~b}$ compares the observed radargram with the simulation. Three reflections are predicted by the simulation: a low time-delay, laterally 
inextensive reflection at the north end of the radargram, a faint, high time delay reflection in the center of the radargram, and a low time-delay reflection at the southern end of the radargram that approaches the surface as it progresses southward. All of these reflections overlap with the reflection seen in the observed radargram. Figure 5a indicates that the ground-range projection of the northern reflection corresponds well to the wall of a $30 \mathrm{~km}$ diameter crater to the west of the orbit groundtrack. The central reflection appears to correspond well to the walls of Ma'adim Vallis and an associated tributary to the east of the groundtrack. The southern reflection does not appear to coincide with any clearly visible topographic feature in Fig. 5a, yet the clutter may be originating from crater walls to the west of the groundtrack. The fact that each of these reflections seem to be originating from unrelated topographic features suggests that their overlap with the E reflection may be purely coincidental and that they do not originate from surface outcrops of a large, mostly buried subsurface structure observed in the E reflection.

There are, however, some observations that support the interpretation of the E reflection as a subsurface reflection. The intensity of the reflection decays as the time delay increases (regardless of frequency), which would be expected for a deepening subsurface contact as attenuation increases. The reflection also has a more blurred appearance in the $3.8 \mathrm{MHz}$ radargram, compared to the $2.8 \mathrm{MHz}$ radargram (apparent in Fig. 2), a possible indication of subsurface volume scattering. Furthermore, there is an apparent latitudinal continuity between this reflection and those in adjacent radargrams: $\mathrm{C}$ and $\mathrm{D}$, located 40 and $30 \mathrm{~km}$ west of the $\mathrm{E}$ reflection respectively. The $\mathrm{C}$ and $\mathrm{D}$ reflections differ from $\mathrm{E}$ in that they are initially flat at their outer edges but steepen dramatically inward, with a gap at the center separating them, making them resemble hyperbolas. Like E, neither of the reflections corresponds to the surface geology or off-nadir topography in any way. Figure $1 \mathrm{~b}$ positions the three radargrams at their correct latitudes relative to each other, and shows that the 
latitudinal positions and extents of the 'arms' of the $\mathrm{C}$ and $\mathrm{D}$ reflections are broadly consistent with those of the 'arms' of the E reflection. There is an apparent consistency between the morphologies of the reflections: the fact that the $\mathrm{C}$ and $\mathrm{D}$ reflections dip down below detection at their centers may be a continuation of the effect seen in the E reflection, where the two ends flatten out and meet at the center.

Despite the consistency that exists between them, the eccentric appearance of these reflections (particularly the tenuous $\mathrm{C}$ and $\mathrm{D}$ reflections) and the absence of similar reflections in radargrams located a few tens of kilometers to the east and west (I and K, Fig. 1d) weaken the hypothesis that they arise from a subsurface interface. The potential for ionospheric distortion to explain their origin will be discussed in section 4.4.

\subsection{Radargrams 6145 (F), 4775 (G) and 2665 (H)}

The positions of the radargrams F, G and H (Fig. 1c) virtually coincide with Ma'adim Vallis, and surface clutter from the channel is seen within them. Radargram G displays two reflections that constitute laterally extensive parabolic reflections (each more than $650 \mathrm{~km}$ across) that thicken as their time delay increases such that the time delay between the top and bottom of the reflections reaches $>10 \mu \mathrm{s}$. The reflections reach a maximum one-way time delay below the surface reflection of $49 \mu \mathrm{s}$. The reflections join at their tips, and the southern tip of the southern reflection dips back downwards before it reaches the surface, terminating below the surface at a one-way time delay of $39 \mu \mathrm{s}$. Radargram $\mathrm{H}$, located just $5 \mathrm{~km}$ to the east of $\mathrm{G}$, does not display a parabolic reflection; instead, it shows a strong, linear reflection that dips to the north, virtually in the same location and at the same time delay as the south limb of the northern parabolic $\mathrm{G}$ reflection. The reflection reaches a maximum one-way time delay of $35 \mu \mathrm{s}$, and appears to extend to the surface (although it becomes tenuous and 
indistinct as it nears the surface). Another potential, but much more tenuous, reflection occurs to the south and appears to correspond to the position of the north limb of the southern

$\mathrm{G}$ reflection. Radargram $\mathrm{F}$ displays an anomaly among all the Ma'adim reflections. A single, high intensity, well-defined, $140 \mathrm{~km}$ long reflection exists at a one-way time delay of $31 \mu \mathrm{s}$, virtually the same time delay as the southern $\mathrm{G}$ reflection that coincides with the $\mathrm{F}$ reflection.

Figure 1c shows that there is an apparent consistency between the time-delays and latitudinal positions of the reflections in these three radargrams. This would suggest a shared origin for the reflections. However, none of them appear to correspond to the surface geology or off-nadir topography in any way. Furthermore, the continuity is undermined by the fact that radargram M (Fig. 1d), whose groundtrack coincides exactly with that of G, shows no apparent reflections that resemble those seen in radargrams F, G or H. Considered along with the erratic morphologies of the reflections, this strongly suggests that the F, G and $\mathrm{H}$ reflections are not subsurface reflections as they would be expected to be seen in all radargrams that pass over this location, supporting the hypothesis that they may arise entirely from ionospheric effects.

\subsection{Ionospheric distortion in the Ma'adim Vallis radargrams}

The influence of the ionosphere is an important factor that must be considered when interpreting MARSIS radargrams. MARSIS performs subsurface studies optimally on the nightside, since the dayside ionosphere does not allow the propagation of frequencies below 3.5 $\mathrm{MHz}$ (the typical peak plasma frequency of the ionosphere on the dayside (Safaeinili et al., 2007)) thereby limiting penetration capabilities (Picardi et al., 1998). The waves that do reach the surface on the dayside will be both attenuated and dispersed by the ionosphere 
(Safaeinili et al., 2007). The dispersion is caused by the frequency dependence of the radio wave propagation speed in the ionosphere (Budden, 1985) and acts to 'smear out' surface and subsurface reflections. The escalating effect of this dispersion on the surface reflection as Mars Express passes from the nightside to the dayside is shown in Safaeinili et al. (2007).

Despite the fact that the subsurface mode of MARSIS is mainly active on the nightside, it does sometimes remain in operation a short distance into the dayside hemisphere. The possibility that the elevated daytime ionospheric plasma frequency might play a role in the production of the reflections seen in the Ma'adim Vallis region was explored by comparing the solar elevation angles for radargrams with and without reflections (shown in Table 2). Of the radargrams that did show reflections, all but one were obtained on the nightside. Of the radargrams that did not show reflections, three were obtained on the nightside while two were obtained on the dayside, albeit at solar elevation angles of less than $10^{\circ}$. This indicates that no clear relationship exists between the ionospheric plasma frequency and the appearance of reflections in the radargrams: reflections were present and absent in both daytime and nighttime radargrams.

The ionosphere can affect the radio waves transmitted by MARSIS in ways other than dispersion and attenuation. Krymskii et al. (2004) described results of the Radio Science experiment aboard Mars Global Surveyor that indicated a correlation between the variability of ionospheric parameters and crustal magnetic field direction (Mitchell et al., 2001). These observations were confirmed by the Active Ionospheric Sounding (AIS) experiment on MARSIS, which recorded the delay times to echoes of radio waves reflected off the ionosphere as a function of frequency (Nielsen et al., 2007). Two traces were often present in spectrograms of the Martian ionosphere: one corresponding to reflections from the nadir, the other originating from a localized reflector in the ionosphere. Gurnett et al. (2005) and Nielsen et al. (2007) found that the localized reflectors are associated with regions of near- 
vertical crustal magnetic fields, which create steep cusps in the electron isodensity in the ionosphere.

Safaeinili et al. (2007) mapped the near-global distribution of the total electron count in the ionosphere on the nightside. The data provide a global view of the relationship between the crustal magnetic field and the electron content in the ionosphere on the nightside. Safaeinili et al. (2007) reported the presence of cusp-like regions of high electron concentrations similar to those described by Nielsen et al. (2007), and interpreted them as being caused by the connection of solar wind to the Martian nightside ionosphere. They observed that these regions frequently occur where the crustal magnetic field has a large vertical component, consistent with the hypothesis of Nielsen et al. (2007).

We suggest that the cusp-like regions of elevated electron concentration in the ionosphere may play a role in producing the reflections seen in the radargrams described in sections 4.2 and 4.3. The Ma'adim Vallis region is located in a part of Mars with elevated crustal magnetic anomalies, with the most intense magnetic crustal sources (producing maximum magnetic anomalies $>100 \mathrm{nT}$ at $400 \mathrm{~km}$ altitude) lying in the Terra Sirenum region, which has Ma'adim Vallis situated at its northern boundary (Acuña et al., 1999; Connerney et al., 2005). These strong crustal magnetic anomalies have often been found to have a large vertical component (Safaeinili et al., 2007). The anomalies exist as long, E-W-aligned bands of alternating upward- and downward- pointing field lines that extend over several tens of degrees of longitude. It is therefore expected that the ionosphere in this region would have high concentrations of the cusp-like features predicted in Nielsen et al. (2007).

There is a possibility that the radio waves that are yielding the anomalous Ma'adim Vallis reflections are being affected by a mechanism related to that described in Fig. 9 of Nielsen et al. (2007). The figure shows the correlation between the vertical crustal magnetic field lines and the ionospheric electron density for both upwelling and downwelling of the ionosphere. 
The paths of off-nadir radio waves from MARSIS are illustrated reflecting off the sides of the ionospheric cusps, where the electron column is pushed up over the magnetic anomaly. Figure 6 of this study offers a variation on this mechanism whereby the Ma'adim reflections arise by ionospheric refraction of off-nadir waves reflected off the planet's surface rather than by reflection of the waves off the ionospheric inhomogeneity itself. The figure indicates how this could generate a parabolic or hyperbolic reflection in MARSIS data, as the refracted waves would initially have low time delays at the edge of the cusp, which subsequently lengthen as MARSIS moves towards the center of the cusp, and shorten as it moves away from the center. If such ionospheric cusps were present in the Ma'adim Vallis region, the mechanism could explain the exaggerated parabolic and hyperbolic morphologies of the reflections discussed in sections 4.2 and 4.3, yet might not explain as well the shallower, flatter morphologies of the reflections in section 4.1. The fact that a number of the reflections are blurred may be an indication that off-nadir waves with different off-nadir angles are being refracted to varying extents by the ionospheric inhomogeneity, and therefore travelling on paths of varying lengths, resulting in varying time delays for the consequential reflections.

Figures $7 \mathrm{a}$ and $7 \mathrm{~b}$, respectively, superimpose the locations of the MARSIS reflections on maps of the radial component of the magnetic field and of the relative electron distribution (from Fig. 3a of Safaeinili et al. (2007)) whose areas correspond to the same area of the map in Fig. 3 of this study. Figure $7 \mathrm{~b}$ shows that elevated electron counts exist in the west and south-east corner of the Ma'adim Vallis region, whereas the center and south of the map show intermediate electron counts. Virtually the whole of the east and north sections of the map are obscured by a large data gap. The most striking correlation is that the locations of the dips in reflections $\mathrm{C}, \mathrm{D}$ and $\mathrm{E}$ correspond well to a prominent peak in the electron density that reaches $>100 \mathrm{~km}$ across. The large parabola in reflection E occurs directly in the center of the feature, whereas the other two reflections exist to the west of the center. This raises the 
possibility that off-nadir MARSIS signals may be being interfered with by this inhomogeneity in a manner akin to the previously described model.

No such ionospheric inhomogeneities characterize the areas where reflections A, B, F, G and $\mathrm{H}$ occur (although half of $\mathrm{G}$ and most of $\mathrm{H}$ are occupied by the data gap). If these reflections are assumed to result from ionospheric interference, then perhaps the electron density distribution does not remain static, thus explaining why these reflections occur in regions thought to have low ionospheric electron densities as mapped by Safaeinili et al. (2007). Direct penetration of solar wind into the atmosphere (and hence ionosphere) of an unmagnetized planet is a viable form of interaction between the two (Michel, 1971). Therefore, as the flux of solar wind arriving at Mars fluctuates due to changing solar activity, localized elevations in electron concentration may form and disperse at different locations in the ionosphere, perhaps amplifying the concentrations of pre-existing inhomogeneities. This would make the inhomogeneities in the ionosphere transient phenomena, along with the reflections associated with them. Indeed, this may explain why other radargrams obtained in the Ma'adim Vallis area do not display subsurface reflections of any type.

While no data exist for the solar wind pressure at Mars during the times these reflections were recorded, a proxy has been developed by Brain et al. (2005) which uses Mars Global Surveyor magnetometer data to extract upstream solar wind pressure for each orbit. This represents the best estimate of the solar wind pressure in the absence of any specific data. Brain et al. (2005) assumed that upstream solar wind pressure is directly related to magnetic pressure in the Martian interaction region where the solar wind current encounters the ionosphere: the higher the solar wind pressure, the higher the magnitude of the subsolar magnetic field as a result of compression of the magnetic field lines. The values for subsolar field strength up to October 2006 (the point at which MGS failed) are published at http://sprg.ssl.berkeley.edu/ brain/proxies/subsolfield.html. This period incorporates the 
times at which radargrams $\mathrm{B}, \mathrm{D}, \mathrm{E}, \mathrm{H}, \mathrm{I}, \mathrm{L}$ and $\mathrm{M}$ were obtained; radargrams $\mathrm{A}, \mathrm{C}, \mathrm{F}, \mathrm{G}, \mathrm{J}$ and $\mathrm{K}$ were obtained after MGS was lost. Table 3 shows the approximate field strength at each of the relevant times: all of the radargrams (with the exception of L) were obtained during times of intermediate field strengths (ranging from $\sim 20 \mathrm{~T}$ to $\sim 60 \mathrm{~T}$ ), with the variation in field strength being equally distributed across radargrams with and without reflections. L was obtained during a strong peak in the field strength $(80 \mathrm{~T})$. In addition to the fact that it was obtained on the dayside (sun elevation of $0.49^{\circ}$ to $7.76^{\circ}$ ), this may explain the strong interference apparent in the L radargram. Yet the overall absence of any correlation relating the occurrence of reflections and periods of high subsolar magnetic field strength reduces the potential for interference caused by solar wind supplementation of the ionosphere to be their cause. However, there remains the possibility that the magnetic field proxy is not entirely efficient in acting as a proxy for the solar wind pressure. Brain et al. (2005) pointed out that the proxy does assume unvarying solar wind pressure conditions over the two hour timespan of the MGS orbit. There is also the potential for an alternative scenario whereby varying solar X-ray fluxes rather than varying solar wind fluxes may be contributing to changing levels of ionization in the ionosphere, yet no X-ray flux data for Mars currently exists.

However, a question that is not adequately answered by the ionospheric distortion hypothesis is why such strong reflections should cluster in the Ma'adim Vallis region. The electron density distribution in the Ma'adim Vallis region is not unique from that in surrounding areas. Similar interference reflections would be expected in the radargrams further to the south of the Ma'adim Vallis region $\left(35^{\circ} \mathrm{S}\right.$ to $\left.85^{\circ} \mathrm{S}\right)$, where magnetic anomalies are stronger (the strongest reaching $>100 \mathrm{nT}$ at $400 \mathrm{~km}$ altitude (Connerney et al., 2005)). Such reflections are entirely absent from this southerly region, or indeed from anywhere else in the immediate surroundings. This might indicate that ionospheric distortion is not sufficient on its own to explain these reflections. The localized spatial correlation of the 
reflections in these eight radargrams might indicate that they are manifestations of subsurface interfaces that have no surface expression.

The reflections cannot realistically be considered undistorted nadir subsurface reflections primarily because of their eccentric morphologies and the very large time delays that they reach. Even if the surface layer were comprised of an exotic, low-attenuation geological material such as ice or high-porosity rock (which is not the case based on the results of the geological mapping of the Ma'adim Vallis area), it is virtually impossible that the radio waves could penetrate to such high time delays due to volume scattering alone. Further evidence against the reflections originating from the subsurface in any way (whether distorted or undistorted) is that there are additional radargrams devoid of subsurface reflections between and near those radargrams displaying strong reflections, combined with the abrupt disappearance of the reflections in radargrams to the east and west of longitudes $177^{\circ} \mathrm{E}$ and $173.5^{\circ} \mathrm{E}$ respectively. The echo strength of the reflections is too high and the spacing between reflections (in combination with their large lateral extents) too close to explain the absence of the reflections in radargrams $\mathrm{I}, \mathrm{J}, \mathrm{K}, \mathrm{L}$ and $\mathrm{M}$ as a consequence of varying dielectric contrasts at the interface. Thus, while no definite relationship has been detected between the appearance of the reflections and ionospheric electron content or solar activity, these facts appear to decisively undermine a subsurface origin. While there is the potential for temporal variability in the properties of the ionosphere, none should exist for the subsurface.

\subsection{Comparison with northern plains reflections recorded by MARSIS}

Large parabolic reflections similar to reflections $\mathrm{E}$ and $\mathrm{G}$ have been observed elsewhere across Mars, for example radargrams 3960 and 3949 located to the east of Ma'adim Vallis at 
$21^{\circ} \mathrm{S}, 160^{\circ} \mathrm{E}$. The Ma'adim reflections also share some characteristics with the parabolic reflections observed in radargrams across the northern plains, which Watters et al. (2006) interpreted to be manifestations of eleven buried basins. These radargrams show multiple, overlapping, smoothly curved, parabolic reflections that reach lateral distances of hundreds of kilometers and extend to varying, but generally large ( $\geq 80 \mu \mathrm{s})$, time delays (see Fig. 8). Watters et al. (2006) interpreted the parabolic reflections to represent off-nadir echoes of a buried basin rim, while in the case of radargram 1903, a flat reflection was interpreted as a nadir echo of the floor of a basin (see Figs. 2 and 3 in Watters et al. (2006) and Fig. 4 in Picardi et al. (2005)). Reflections were also seen in the adjacent radargram of orbit 1892 , which Watters et al. (2006) regarded as being additional support for the hypothesis that the reflections resulted from a single buried basin that both orbits passed over. However, radargram 3819, whose groundtrack is located $\sim 45 \mathrm{~km}$ to the west of that of radargram 1903, and which should pass over the buried basin hypothesized in Watters et al. (2006), shows no sign of any parabolic reflections that were so apparent in 1892 and 1903 . While the morphologies and time delays of the northern plains reflections make a convincing case for a buried basin origin, the inconsistency of their occurrence lends the same uncertainty to them as it does to the Ma'adim reflections. Alternatively, they may result from the ionospheric refraction mechanism presented here as an explanation for the Ma'adim reflections. The difference is that in some cases echoes would be refracted by more than one inhomogeneity, producing multiple parabolas with different time delays (as in radargrams 1892 and 1903). This would not, however, satisfactorily explain the flat reflection seen in 1903. Furthermore, the map of ionospheric electron density in Fig. 3a of Safaeinili et al. (2007) indicates that the electron density over the northern plains generally appears to be homogeneous and presents much smaller-magnitude anomalies relative to the Ma'adim Vallis region. 


\section{Conclusion}

Reflections seen in several MARSIS radargrams recorded over the Ma'adim Vallis area of Mars have been studied in order to determine whether they result from subsurface structure or ionospheric effects. Virtually all the reflections display morphological, locational and temporal characteristics that do not allow them to be explained entirely by either ionospheric or subsurface influences.

Radargrams A and B, whose groundtracks overlap nearly exactly, display shallow, fairly flat, relatively laterally inextensive reflections that occupy similar locations on the ground in the two radargrams. These characteristics of the reflections would support a subsurface origin, and the southern reflections do appear to coincide well with the location of Eridania Planitia (and may therefore represent the base of the deposits hypothesized to be filling the basin), yet the northern reflections have no apparent surface manifestation. Furthermore, the reflections are not manifested in other radargrams located a short distance to the east and west.

Reflections in six other MARSIS radargrams (C, D, E, F, G and H) have exaggerated, tenuous morphologies; none of these can be correlated with the surface geology or off-nadir topography. The reflections cluster in a localized area and a fairly well-defined latitudinal continuity exists between them. Ionospheric distortion has undoubtedly influenced the morphologies of the reflections, and it is suggested that refraction of off-nadir surfacereflected waves by inhomogeneities in the ionospheric electron density may stand as a reasonable explanation for the parabolic and hyperbolic shapes, large time delays and often blurred appearances of the reflections. While the localized distribution might suggest that a discrete subsurface interface is producing the reflections, which have subsequently been distorted by ionospheric interference, this hypothesis is significantly weakened by the 
presence of 'barren' radargrams in the close vicinity of the reflection-bearing radargrams. This paradox also characterizes the parabolic reflections seen in MARSIS radargrams in the northern plains.

Conversely, if these reflections were caused by ionospheric effects alone, similar reflections would be expected in several other locations across Mars where strong inhomogeneities in the ionospheric electron density occur. These facts prevent the establishment of a definite origin of the reflections observed in the Ma'adim Vallis region. However, a strong case can be made again against a subsurface origin, leaving ionospheric distortion as the only realistic cause. The reason behind the apparent random timing of their appearance is uncertain; an attempt to use MGS measurements of the Martian subsolar magnetic field as a proxy for solar wind pressure did not find an association with the appearance of the reflections, yet this does not rule out that solar activity is not in some way influential.

\section{Acknowledgements}

Thanks are offered to Dr Mario Acuña and Dr Jared Espley (Goddard Space Flight Center) for advice regarding Martian solar wind data, Dr Anton Ivanov (Planetary Science Institute, Lausanne, Switzerland) for advice regarding the MAPPS program and for supplying the offnadir ground projection diagrams, and Dr Ian Crawford (UCL/Birkbeck Research School of Earth Sciences) for additional comments on the original manuscript. MARSIS is managed by the Agenzia Spaziale Italiana (ASI) and the National Aeronautics and Space Administration (NASA). The Mars Express mission is managed and operated by the European Space Agency (ESA). The research activities of the MARSIS PI and Italian investigators are supported by grants under the Mars Express /ASI program. Work of the U.S. investigators is 
supported by grants under the Mars Express/NASA project. The Science and Technology Facilities Council is also acknowledged for supplying some of the funding that made this study possible.

\section{References}

Acuña, M.H., and 12 colleagues, 1999. Global Distribution of Crustal Magnetization Discovered by the Mars Global Surveyor MAG/ER Experiment. Science 284, 790-793.

Brain, D.A., Halekas, J.S., Lillis, R., Mitchell, D.L., Lin, R.P., Crider, D.H., 2005. Variability of the altitude of the Martian sheath. Geophys. Res. Lett. 32, L18203, doi:10.1029/2005GL023126.

Budden, K.G., 1985. The Propagation of Radio Waves, Cambridge Univ. Press, New York.

Cabrol, N.A., Grin, E.A., Dawidowicz, G., 1996. Ma'adim Vallis Revisited through New Topographic Data: Evidence for an Ancient Intravalley Lake. Icarus 123, 269-283.

Connerney, J.E.P., Acuña, M.H., Ness, N.F., Kletetschka, G., Mitchell, D.L., Lin, R.P., Reme, H., 2005. Tectonic implications of Mars crustal magnetism. Proc. Natl. Acad. Sci. USA 102 , no. $42,14970-14975$.

Daniels, D.J., 2004. Ground Penetrating Radar, $2^{\text {nd }}$ edition, pub. The Institution of Electrical Engineers, London. 
De Hon, R.A., 1977. Geologic Map of the Eridania Quadrangle of Mars. U.S. Geol. Survey. Invest. Ser. Map, I-1008 (MC-29).

Frey, H.V., Roark, J.H., Shockey, K.M., Frey, E.L., Sakimoto, S.E.H., 2002. Ancient lowlands on Mars. Geophys. Res. Lett. 29, no. 10, 1384, doi:10.1029/2001GL013832.

Gurnett, D.A., Kirchner, D.L., Huff, R.L., Morgan, D.D., Persoon, A.M., Averkamp, T.F., Duru, F., Nielsen, E., Safaeinili, A., Plaut, J.J., Picardi, G., 2005. Radar soundings of the ionosphere of Mars. Science 310, 1929-1933.

Heggy, E., Paillou, P., Costard, F., Mangold, N., Ruffie, G., Demontoux, F., Grandjean, G., Malézieux, J.M., 2003. Local geoelectrical models of the Martian subsurface for shallow groundwater detection using sounding radars. J. Geophys. Res. 108, no. E4, 8030, doi:10.1029/2002JE001871.

Heggy, E., Clifford, S.M., Grimm, R.E., Dinwiddie, C.L., Wyrick, D.Y., Hill, B.E., 2006. Ground-penetrating radar sounding in mafic lava flows: Assessing attenuation and scattering losses in Mars-analog volcanic terrains. J. Geophys. Res. 111, E06S04, doi:10.1029/2005JE002589.

Howard III, J.H., 1979. Geologic Map of the Phaethontis Quadrangle of Mars. U.S. Geol. Survey. Invest. Ser. Map, I-1145 (MC-24). 
Irwin III, R.P., Maxwell, T.A., Howard, A.D., Craddock, R.A., Leverington, D.W., 2002. A Large Paleolake Basin at the Head of Ma'adim Vallis, Mars. Science 296, 2209-2212.

Irwin III, R.P., Howard, A.D., Maxwell, T.A., 2004. Geomorphology of Ma'adim Vallis, Mars, and associated paleolake basins. J. Geophys. Res. 109, E12009, doi:10.1029/2004JE002287.

Jones, T.K., Gregg, T.K.P., Crown, D.A., 2007. A quantitative investigation of fluvial activity in the Hesperia Planum region, Mars. LPSC XXXVIII, abstract \#2156.

Krymskii, A.M., Ness, N.F., Crider, D.H., Breus, T.K., Acuña, M.H., Hinson, D.P., 2004. Solar wind interaction with the ionosphere/atmosphere and crustal magnetic fields at Mars: Mars Global Surveyor Magnetometer/Electron Reflectometer, radio science and accelerometer data. J. Geophys. Res. 109, A11306, doi:10.1029/2004JA010420.

Langlais, B., Purucker, M.E., Mandea, M., 2004. Crustal magnetic field of Mars. J. Geophys. Res. 109, E02008, doi:10.1029/2003JE002048.

McCoy, T.J., and 18 colleagues, 2008. Structure, stratigraphy, and origin of Husband Hill, Columbia Hills, Gusev Crater, Mars. J. Geophys. Res. 113, E06S03, doi:10.1029/2007JE003041.

Michel, F.C., 1971. Solar wind interaction with planetary atmospheres. Rev. Geophys. Space Phys. 9, 427-35. 
Mitchell, D.L., Lin, R.P., Mazelle, C., Réme, H., Cloutier, P.A., Connerney, J.E.P., Acuña, M.H., Ness, N.F., 2001. Probing Mars' crustal magnetic field and ionosphere with the MGS Electron Reflectometer. J. Geophys. Res. 106, No. E10, 23,419-23,427.

Mutch, T.A., Morris, E.C., 1979. Geologic Map of the Memnonia Quadrangle of Mars. U.S. Geol. Survey. Invest. Ser. Map, I-1137 (MC-16).

Nielsen, E., Wang, X.-D., Gurnett, D.A., Kirchner, D.L., Huff, R., Orosei, R., Safaeinili, A., Plaut, J.J., Picardi, G., 2007. Vertical sheets of dense plasma in the topside Martian ionosphere. J. Geophys. Res. 112, E02003, doi:10.1029/2006JE002723.

Picardi, G., Plaut, J.J., Johnson, W.T.K., Borgarelli, L., 1998. Mars Express SSRA Proposal.

Picardi, G., and 33 colleagues, 2005. Radar Soundings of the Subsurface of Mars. Science 310, 1925-1928.

Plaut, J.J, and 23 colleagues, 2007a. Subsurface radar sounding of the south polar layered deposits of Mars. Science 316, 92-95.

Plaut, J.J., Ivanov, A., Safaeinili, A., Milkovich, S.M., Picardi, G., Seu, R., Phillips, R., 2007b. Radar Sounding of Subsurface Layers in the South Polar Plains of Mars: Correlation with the Dorsa Argentea Formation. Lunar Planet. Sci. XXXVIII, abstr. 2144. 
Safaeinili, A., Kofman, W., Mouginot, J., Gim, Y., Herique, A., Ivanov, A.B., Plaut, J.J., Picardi, G., 2007. Estimation of the total electron content of the Martian ionosphere using radar sounder surface echoes. Geophys. Res. Lett. 34, L23204, doi:10.1029/2007GL032154.

Scott, D.H., Morris, E.C., West, M.N., 1978. Geologic Map of the Aeolis Quadrangle of Mars. U.S. Geol. Survey. Invest. Ser. Map, I-1111 (MC-23).

Watters, T.R., Leuschen, C.J., Plaut, J.J., Picardi, G., Safaeinili, A., Clifford, S.M., Farrell, W.M., Ivanov, A.B., Phillips, R.J., Stofan, E.R., 2006. MARSIS radar sounder evidence of buried basins in the northern lowlands of Mars. Nature 444, 905-908.

Watters T.R., and 12 colleagues, 2007. Radar Sounding of the Medusae Fossae Formation Mars: Equatorial Ice or Dry, Low-Density Deposits? Science 318, 1125-1128.

Zhang, Z., Hagfors, T., Nielsen, E., Picardi, G., Mesdea, A., Plaut, J.J., 2008. Dielectric properties of the Martian south polar layered deposits: MARSIS data inversion using Bayesian inference and genetic algorithm. J. Geophys. Res. 113, E05004, doi:10.1029/2007JE002941. 
Figure captions

Figure 1. MARSIS radargrams from orbits in the Ma'adim Vallis region displaying the variety of echoes seen. Radargrams are grouped into four sections according to their locations and reflection characteristics: (a) The central radargrams 4786 (A) and 2676 (B), displaying shallow and relatively laterally inextensive reflections. (b) The westerly radargrams $4808(C), 3024(\mathrm{D})$ and $2687(\mathrm{E})$, displaying reflections that reach to large time delays and show tenuous, parabolic and hyperbolic morphologies. (c) The easterly radargrams $6145(\mathrm{~F}), 4775(\mathrm{G})$ and $2665(\mathrm{H})$, displaying similarly deep, parabolic and tenuous reflections. (d) Radargrams 2698 (I), 6163 (J), 4797 (K), 3002 (L) and 2991 (M), which occur in the Ma'adim Vallis region but display no reflections. Radargrams in each group are aligned at the same latitude relative to each other. Radargrams are accompanied by the orbit number, reference letter, frequency band center and groundtrack (horizontal white line) on a shaded relief map of the surface. Locations of the reflections on the surface are shown as white groundtracks in Fig. 3. The width of the shaded relief maps are $100 \mathrm{~km}$. North is at the left end of the radargrams. Vertical white scale bar represents $25 \mu$ s one-way radio wave travel-time. White arrows highlight relevant reflections.

Figure 2. Comparison of the appearances of the E reflection as seen in radargrams obtained at center frequencies of $2.8 \mathrm{MHz}$ and $3.8 \mathrm{MHz}$.

Figure 3. Geological map of the Ma'adim Vallis area with the locations of the MARSIS reflections superimposed. Base map is a Viking image mosaic of sinusoidal projection. 
Figure 4. (a \& c) Ground-range projections of reflections from the B (a) and A (c) radargrams superimposed on a map comprising THEMIS infrared images of the Ma'adim Vallis region. ( $\mathrm{b} \& \mathrm{~d}$ ) Comparisons of simulations of radargrams B (b) and A (d) (above) and the observed radargrams (below). Arrows on the simulations and observed radargrams mark reflections caused by off-nadir surface clutter from Ma'adim Vallis. North is at the left of the radargrams.

Figure 5. (a) Ground-range projection of reflections from the E radargram superimposed on a map comprising THEMIS infrared images of the Ma'adim Vallis region. The dashed circle marks the approximate rim of a QCD identified by Frey et al. (2002). The dotted segments of the reflections indicate where reflections are also seen in the simulation. (b) Comparison of a simulation of radargram E (above) and the observed radargram (below). Arrows on the simulation mark where reflections caused by off-nadir surface clutter are expected. North is at the left of the radargrams.

Figure 6. Schematic of a proposed mechanism for the production of the anomalous morphologies of the Ma'adim reflections. MARSIS radio waves of varying off-nadir angles are refracted to varying extents by ionospheric inhomogeneities, and as such travel on paths of varying distances to the surface before they are reflected back. The magnitude of the refraction varies as Mars Express progresses through the inhomogeneity. (a) Front view. (b) Side view. (c) Top view.

Figure 7. Both maps cover the same area mapped in Fig. 3 of this study. (a) Map of the absolute strength of the radial magnetic field, derived from a model provided by Langlais et al. (2004). Bright areas are regions where the magnetic field is vertical. (b) Detail of the 
electron density distribution map shown in Fig. 3a in Safaeinili et al. (2007). Black areas represent data gaps. TEC is Total Electron Count. The locations of MARSIS reflections (with accompanying orbit reference letters) are overlaid on both maps.

Figure 8. MARSIS radargrams from orbits 1892 and 1903 showing the multiple parabolic reflections (and single flat reflection) seen in Chryse Planitia (located at $37^{\circ} \mathrm{N}, 337^{\circ} \mathrm{E}$ ). The 'barren' radargram from the adjacent orbit 3819 is also shown. The short side of the shaded relief maps measures $100 \mathrm{~km}$ across. North is at the right end of the radargrams. White, vertical bar represents $50 \mu$ s one-way travel time. White line marks the groundtracks of the orbits. 
Table 1. Correlation of MARSIS orbit numbers to the reference letters that will be used throughout the paper.

\begin{tabular}{c|c}
\hline MARSIS orbit no. & Radargram ref. letter \\
\hline 4786 & $\mathrm{~A}$ \\
\hline 2676 & $\mathrm{~B}$ \\
\hline 4808 & $\mathrm{C}$ \\
\hline 3024 & $\mathrm{D}$ \\
\hline 2687 & $\mathrm{E}$ \\
\hline 6145 & $\mathrm{~F}$ \\
\hline 4775 & $\mathrm{G}$ \\
\hline 2665 & $\mathrm{H}$ \\
\hline 2698 & $\mathrm{I}$ \\
\hline 6163 & $\mathrm{~J}$ \\
\hline 4797 & $\mathrm{~K}$ \\
\hline 3002 & $\mathrm{~L}$ \\
\hline 2991 & $\mathrm{M}$
\end{tabular}


Table 2. Sun elevation angles during the times at which radargrams over Ma'adim Vallis were recorded. For radargrams with reflections, the elevation angles displayed are those that existed at either end of the reflection; for radargrams without reflections, the elevation angles displayed are those that existed at either end of the radargram, the limits of which are shown in Fig. 3 ( $\mathrm{N}$ end is at $15^{\circ} 52^{\prime} 29^{\prime \prime} \mathrm{S}, \mathrm{S}$ end is at $35^{\circ} 39^{\prime} 59^{\prime \prime} \mathrm{S}$ ).

\begin{tabular}{c|c|c|c}
\hline $\begin{array}{c}\text { Radargram } \\
\text { ref. letter }\end{array}$ & $\begin{array}{c}\text { Reflections } \\
\text { seen? }\end{array}$ & $\begin{array}{c}\text { Sun elevation at N end of } \\
\text { reflection/radargram }\left({ }^{\circ}\right)\end{array}$ & $\begin{array}{c}\text { Sun elevation at S end of } \\
\text { reflection/radargram }\left({ }^{\circ}\right)\end{array}$ \\
\hline H & Y & -31.90 & -31.19 \\
\hline B & Y & -30.69 & -28.79 \\
\hline E & Y & -29.37 & -28.25 \\
\hline D & Y & 9.65 & 4.99 \\
\hline G & Y & -27.25 & -17.64 \\
\hline A & Y & -20.31 & -18.79 \\
\hline C & Y & -21.96 & -15.96 \\
\hline F & Y & -8.47 & -8.94 \\
\hline I & N & -28.06 & -26.69 \\
\hline M & N & 7.90 & -0.94 \\
\hline L & N & 7.76 & 0.49 \\
\hline K & N & -24.85 & -15.87 \\
\hline J & N & -3.25 & -6.59
\end{tabular}


Table 3. Subsolar magnetic field strengths measured by the magnetometer experiment on board Mars Global Surveyor at the times of acquisition of MARSIS radargrams over the Ma'adim Vallis region.

\begin{tabular}{c|c|c|c}
\hline & $\begin{array}{c}\text { Radargram } \\
\text { ref. letter }\end{array}$ & $\begin{array}{c}\text { Time of radargram } \\
\text { acquisition (UT) }\end{array}$ & $\begin{array}{c}\text { Subsolar magnetic } \\
\text { field strength (T) }\end{array}$ \\
\hline Radargrams & H & 7 Feb 2006, 21:42 & $\sim 33$ \\
displaying & B & 10 Feb 2006, 23:39 & $\sim 60$ \\
reflections & E & 14 Feb 2006, 01:35 & $\sim 30$ \\
& D & 19 May 2006, 10:26 & $\sim 33$ \\
\hline Radargrams not & I & 17 Feb 2006, 03:31 & $\sim 41$ \\
displaying reflections & M & 10 May 2006, 04:41 & $\sim 21$ \\
& L & 13 May 2006, 06:33 & $\sim 80$
\end{tabular}


a)
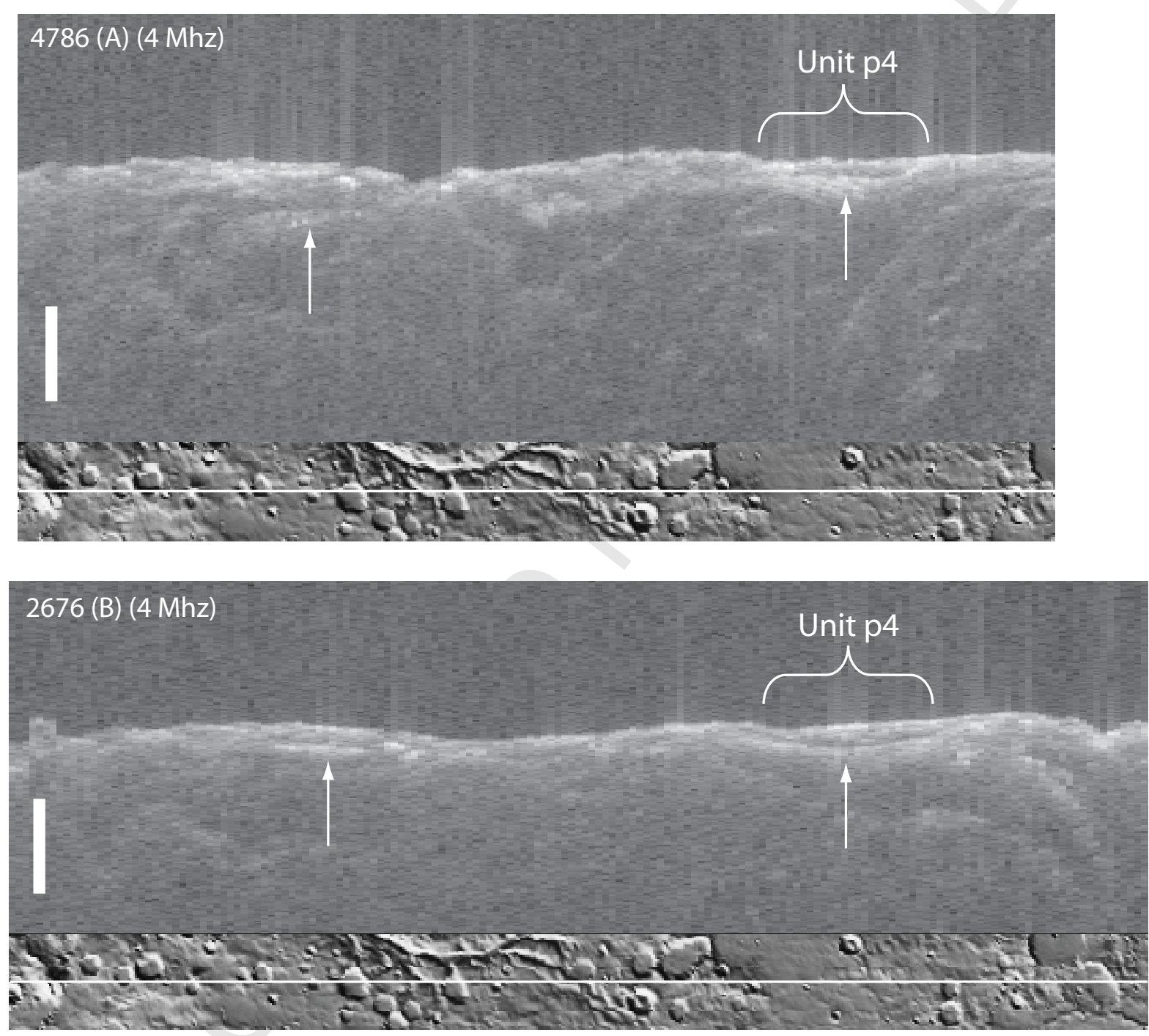


\section{ACCEPTED MANUSCRIPT}

b)

4808 (C) (3 Mhz)
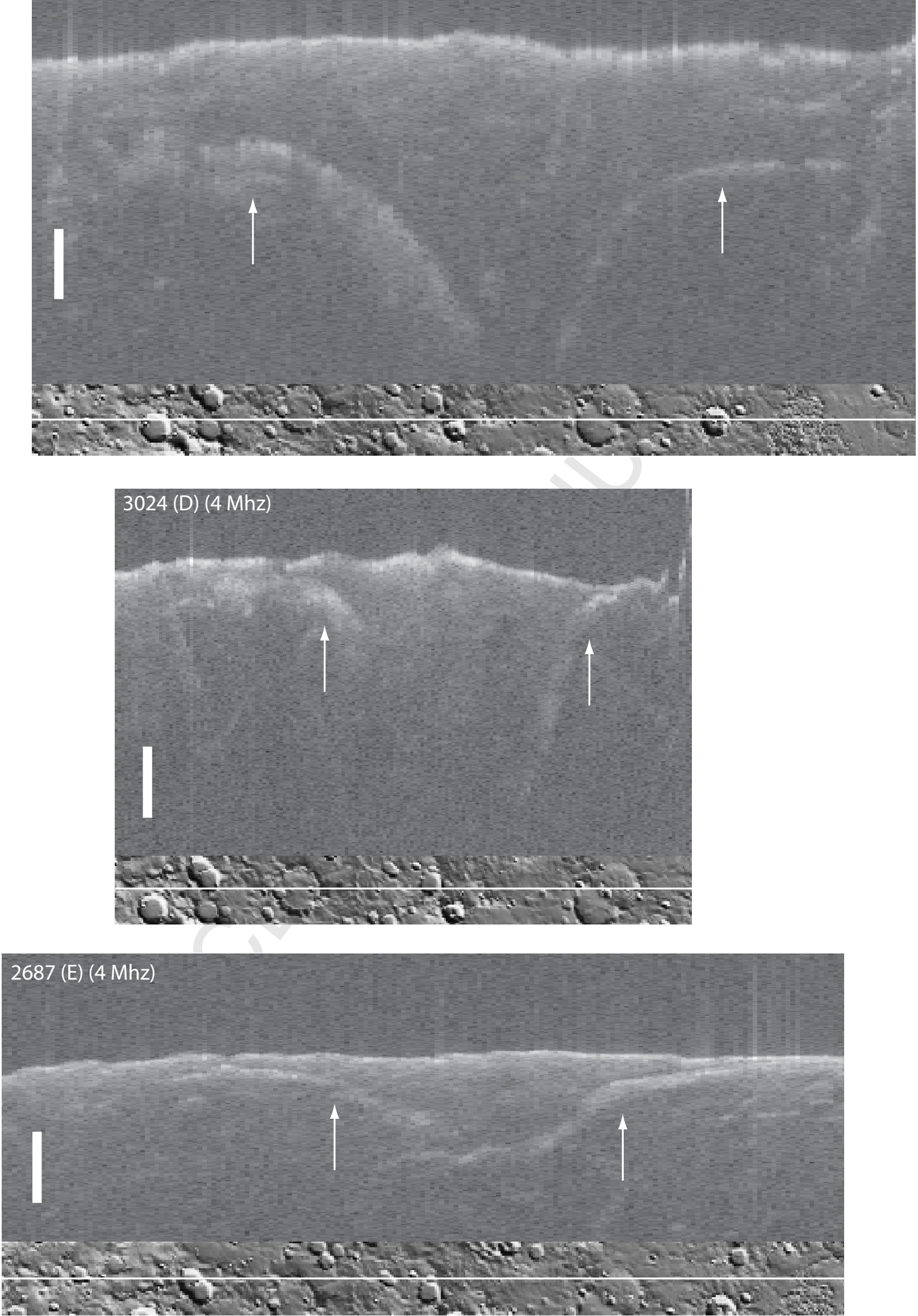


\section{ACCEPTED MANUSCRIPT}

c)
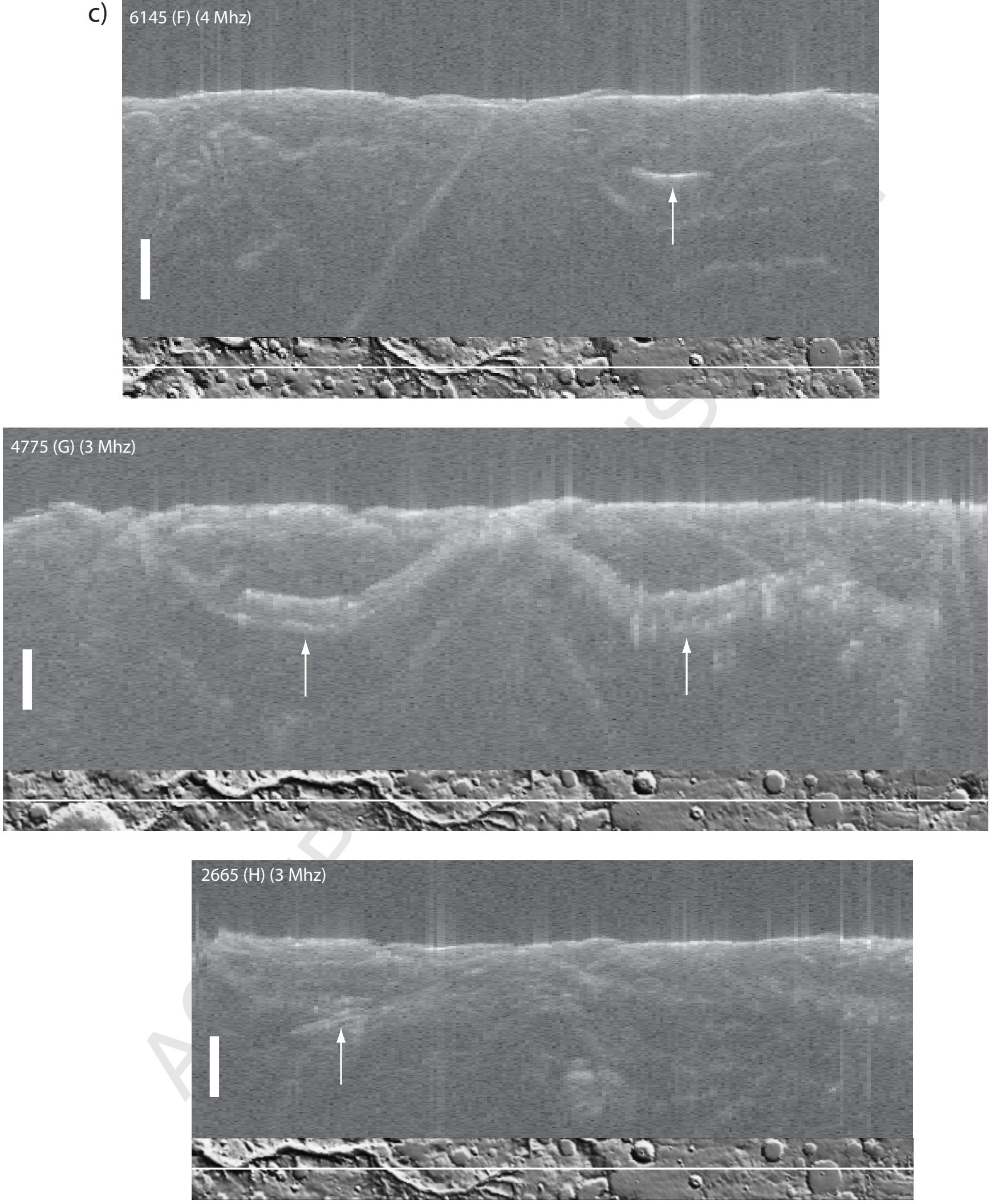


\section{ACCEPTED MANUSCRIPT}

d)
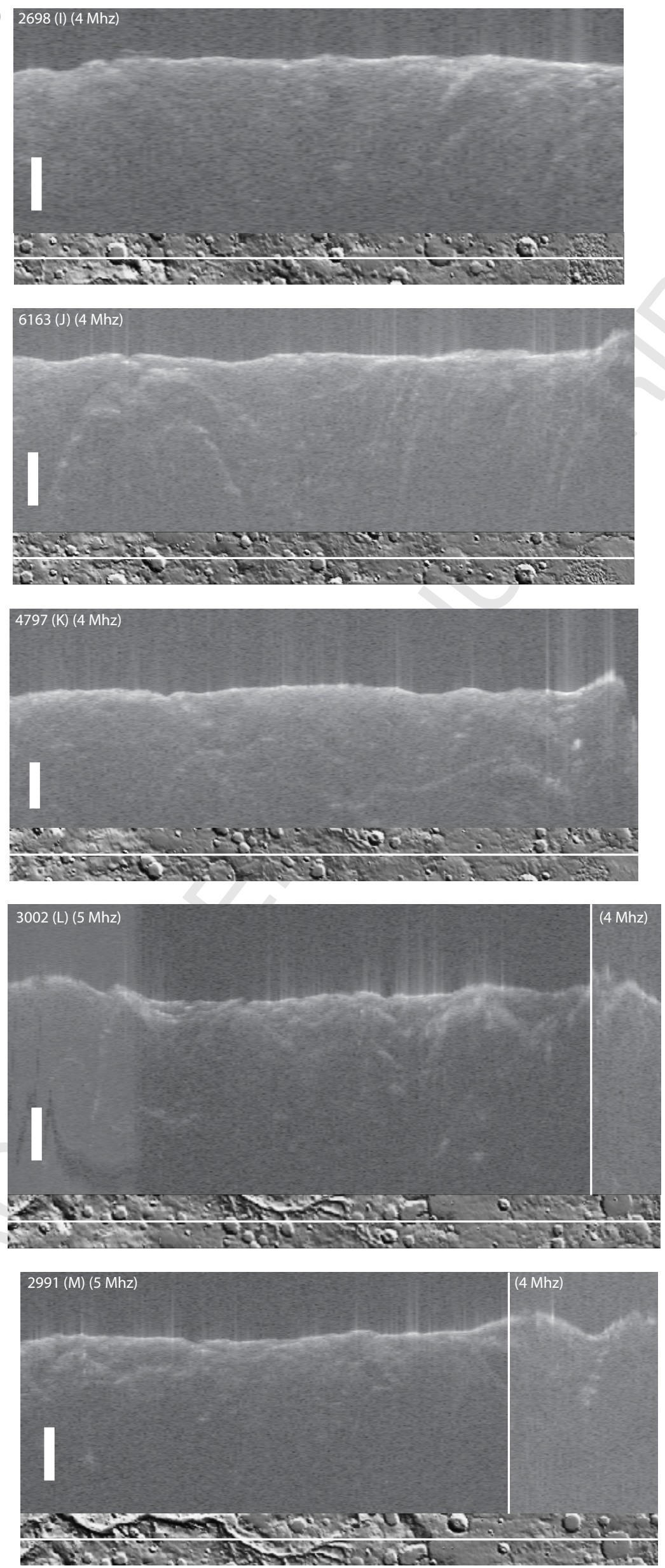


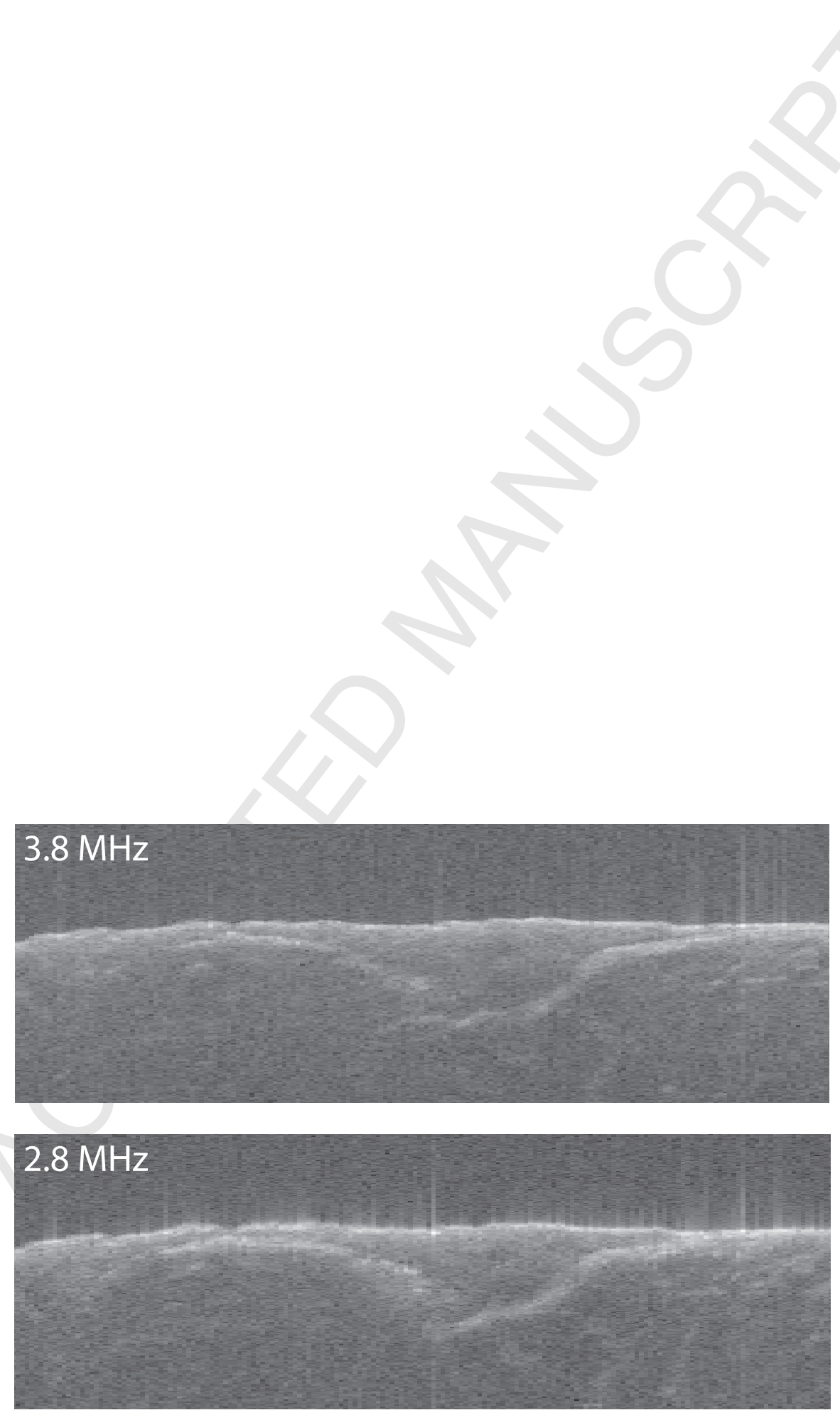




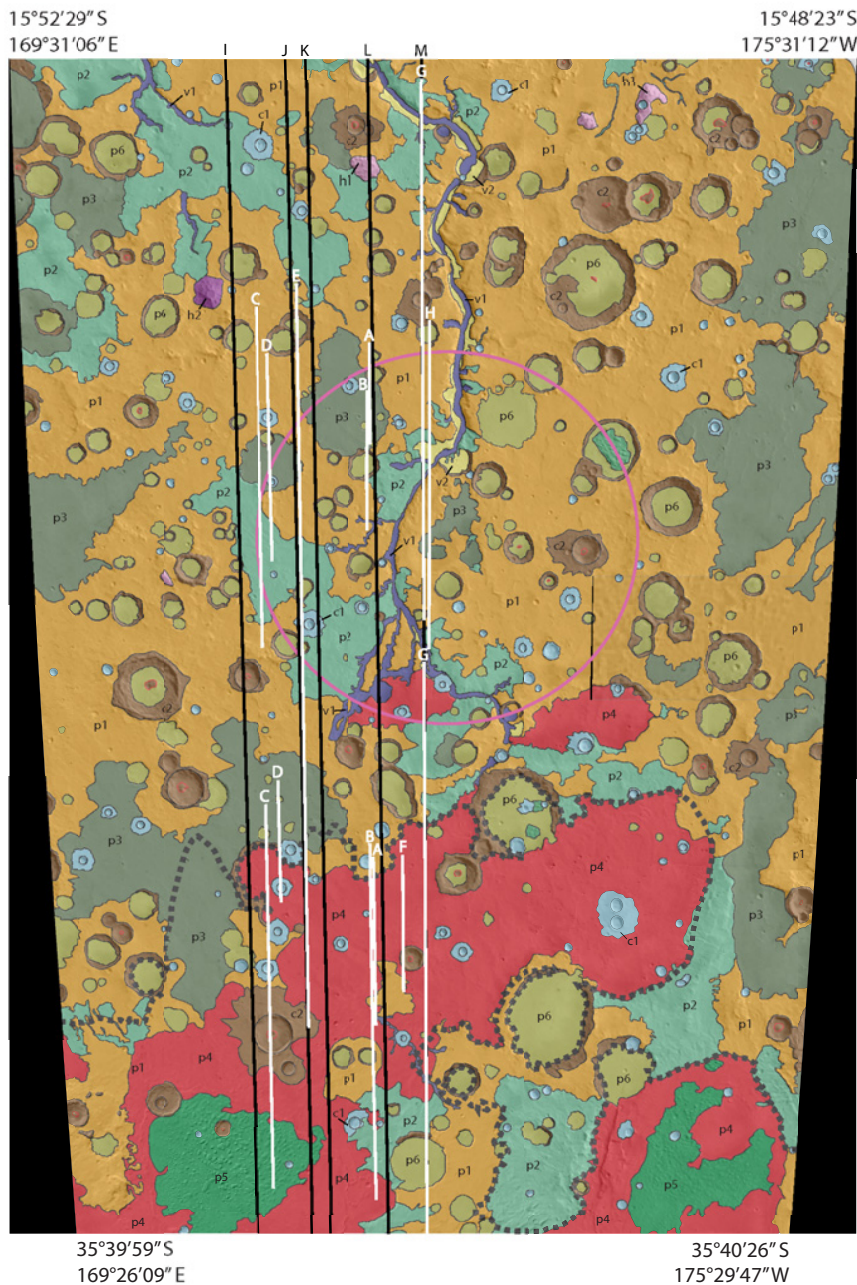

\section{DESCRIPTION OF MAP UNITS}

CRATER MATERIALS

$=1$ FRESH IMPACT CRATER MATERIAL: Sharp, raised, complete rims. Floors bowl-shaped and lower than surrounding terrain. Central peaks and ejecta surrounding terrain. Centrats
blankets often present.

C2 DEGRADED IMPACT CRATER MATERIAL: Eroded, sometimes incomplete rims. Floors flat (filled by unit p6) and at the same elevation as surrounding terrain. Slumping and terracing often seen on walls. Central peaks and ejecta blankets generally not present.

\section{HIGHLAND MATERIALS}

11 MOUNTAINOUS MATERIAL: Forms rugged isolated massifs with high relief reaching $40 \mathrm{~km}$ across, mainly in the north of the mapping area. Interpretation: Remnants of Noachian mountain complexes.

h2 VOLCANIC MATERIAL: Symmetrical cone of Zephyria Tholus, located in NW of mapping area. Circular summit crater is flooded and prominent radial
dissection has affected flanks. Interpretation: Stratovolcano/composite cone of uncertain age.

\section{PLAINS MATERIALS}

01 ROUGH PLAINS MATERIAL: Hummocky, rugged terrain. Features a higher density of large $(>12 \mathrm{~km}$ diameter), eroded impact craters than other units. Wrinkle ridges are seen occasionally. Interpretation: strongly brecciated Noachian crust.

p2 CHANNELED PLAINS MATERIAL: Hummocky, rugged terrain similar to unit $\mathrm{p} 1$, but which displays numerous small valley networks and eroded terraces and mesas. Interpretation: Noachian terrain that has experienced extensive alteration caused by the action of precipitation and/or groundwater sapping (Jones et al., 2007).

p3 RIDGED PLAINS MATERIAL: Smooth, low-relief terrain featuring numerous sharp linear and circular wrinkle ridges. Density of large, eroded impact craters is less than that for unit p1. Interpretation: Flood lavas emplaced in low lying areas of the highlands, possibly during the late Noachian/early Hesperian.

p4 MOTTLED, DISSECTED PLAINS MATERIAL: Smooth, low-relief terrain, generally with a patchy albedo. Unit is eroded and dissected in places to form mesas and terraces. Unit is sometimes seen to subdue the morphology of underlying features (e.g. wrinkle ridges, impact basins, etc.). Exhibits low crater density. Interpretation: Lacustrine sediments deposited during the late Noachian. p5 KNOBBY MESA MATERIAL: Chaotic terrain comprising numerous densely-packed flat-topped mesas and rounded knobs reaching $10 \mathrm{~km}$ across. Abrupt contact exists between the unit and surrounding plains. Exhibits low crater density. Unit generally occurs within unit p4. Interpretation: resistant lacustrine sediments deposited during the late Noachian?

p6 SMOOTH PLAINS: Very smooth, very lightly-cratered surfaces on the floors of degraded impact craters. Interpretation: crater fill material eroded from the sides of large, degraded impact craters.

\section{VALLEY MATERIALS}

v1 VALLEY FLOOR MATERIAL: Smooth, slightly pitted and lightly-cratered deposits forming the floor of Ma'adim Vallis as well as those of tributaries feeding into it and other large channels in the mapping area. other large channels in the mapping area.
Interpretation: sediments deposited by water flowing through valleys during the late Noachian.

v2 VALLEY TERRACE MATERIAL: Smooth, flat terraces located on the walls and in the center of Ma'adim Vallis. Terraces are sometimes lineated perpendicular to the valley wall, and often have fretted margins on the valley side. Interpretation: remnants of resistant geological layers partly eroded by water flowing through Ma'adim Vallis during the late Noachian.

- Geological boundary

Crater rim

Crater central peak

$\square$ Locations of reflections seen in MARSIS radargram (reflections labelled with orbit reference letter)

- Locations of significant radargrams that do not display any reflections (radargrams labelled with orbit reference letter)

... Lake shoreline hypothesized in Irwin et al. (2002)

$$
\begin{gathered}
50{ }_{100}^{150}{ }^{200} \quad 250 \\
\text { Distance }(\mathrm{km})
\end{gathered}
$$

CORRELATION OF MAP UNITS

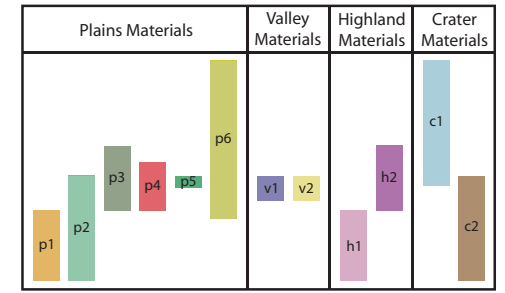


a)

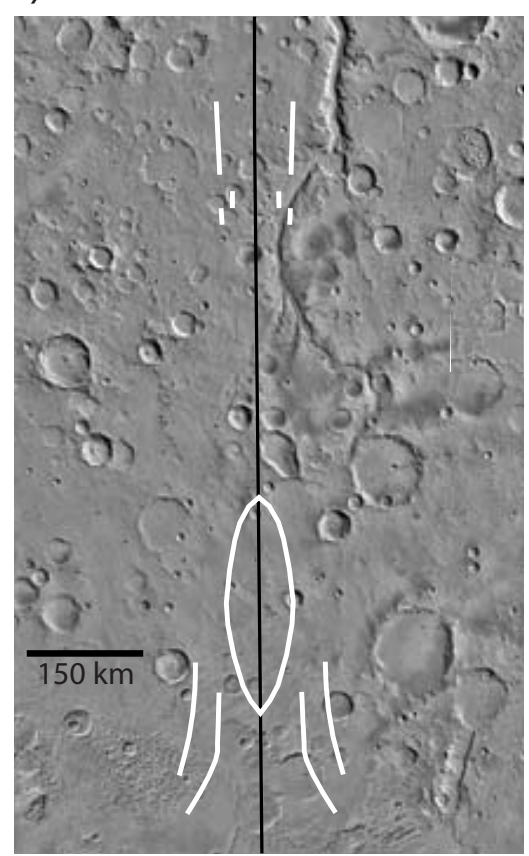

c)

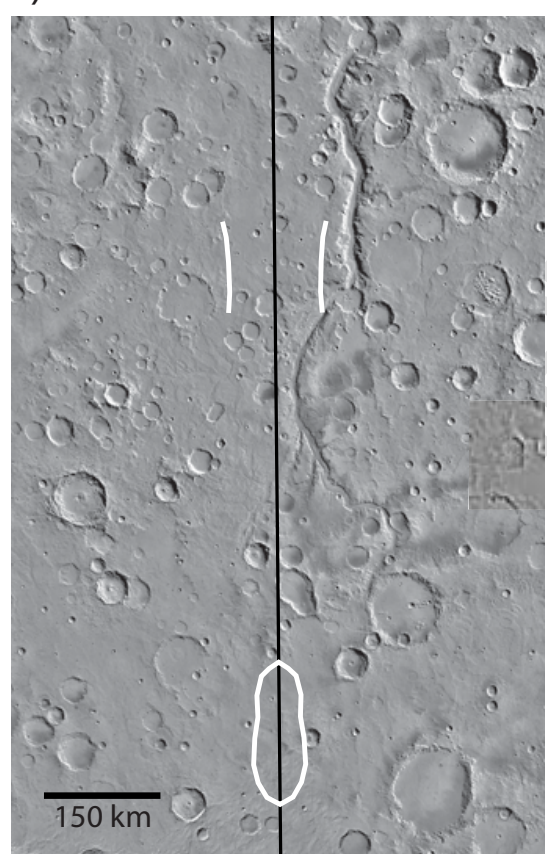

b)
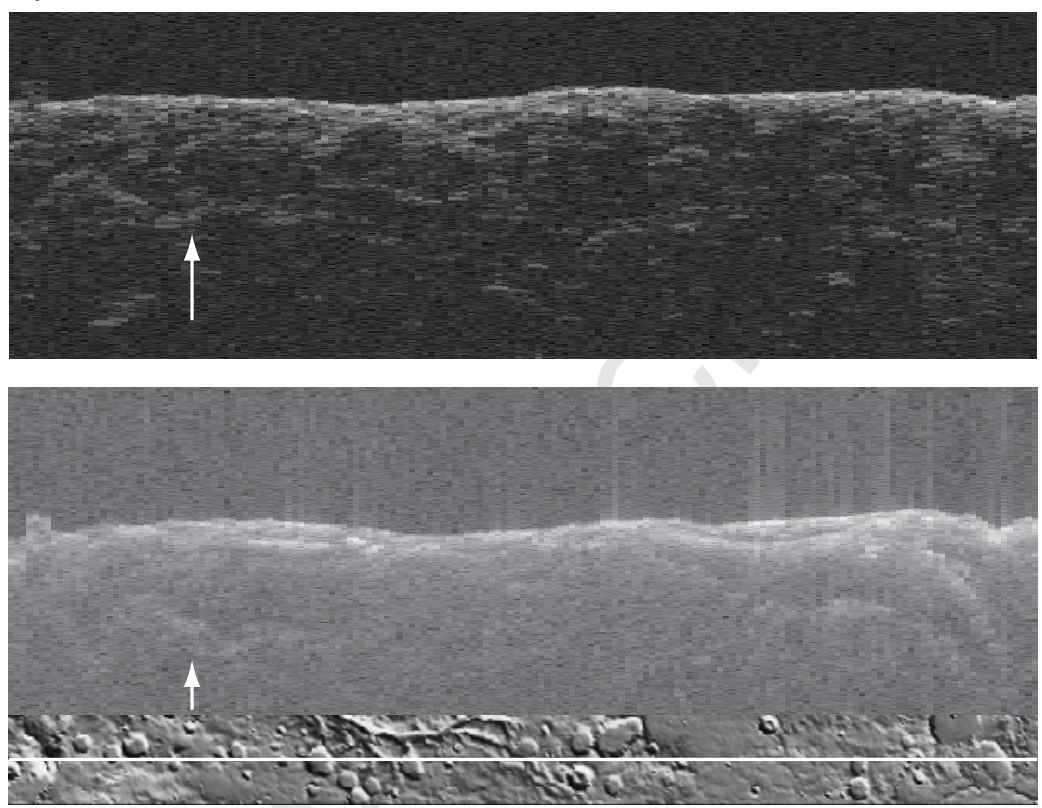

d)
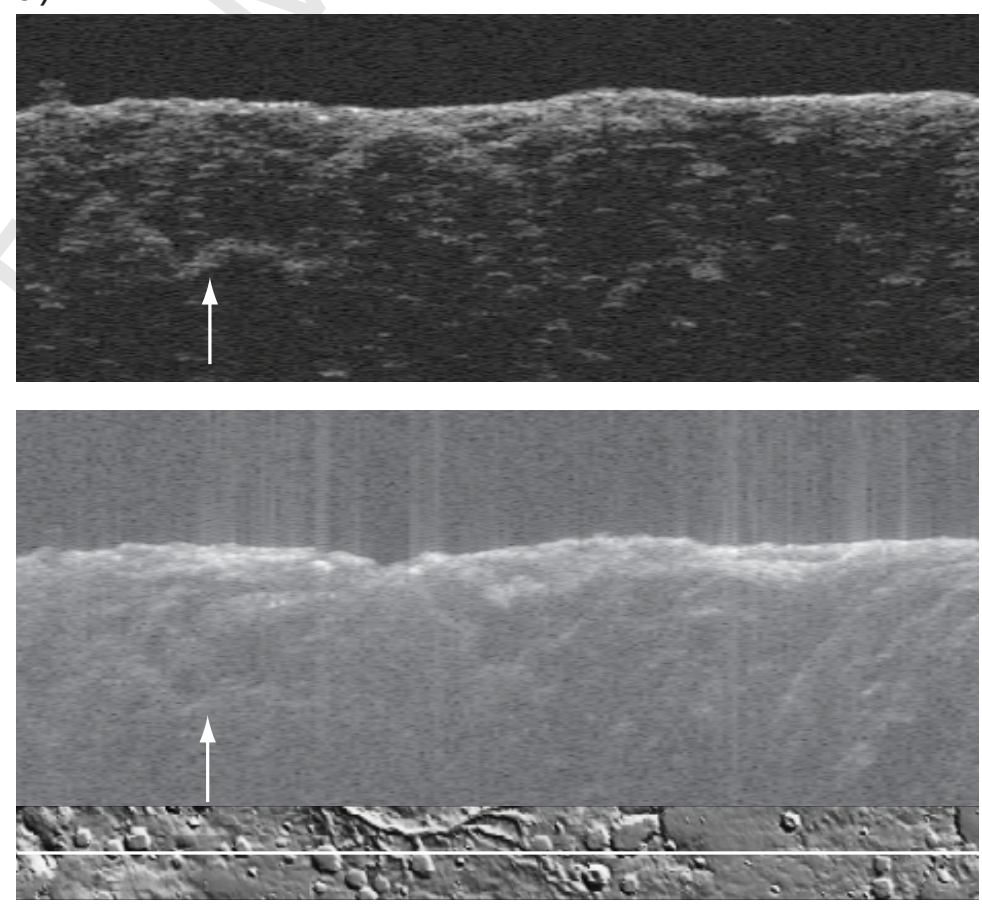
a)

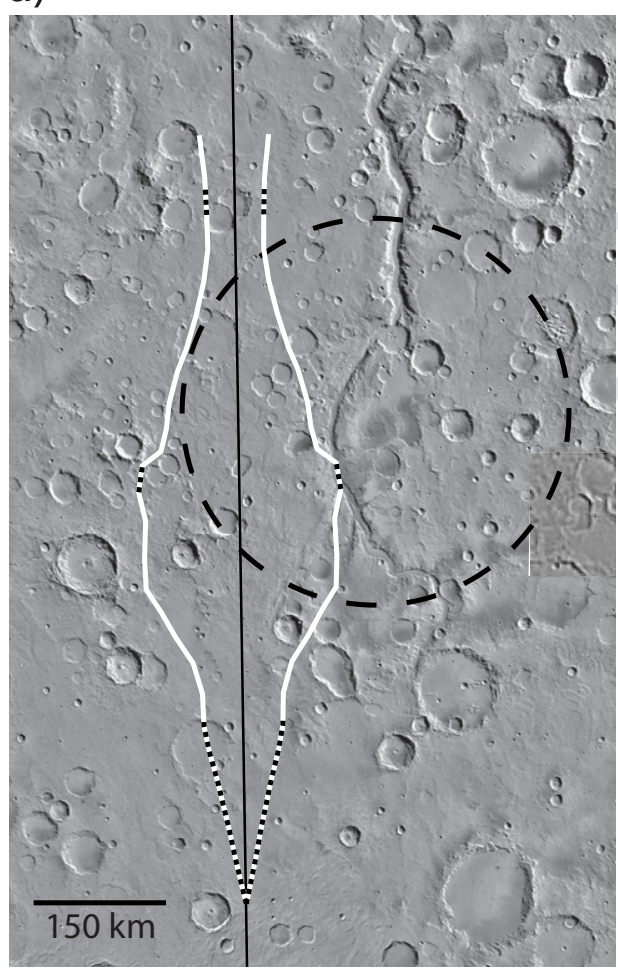

b)
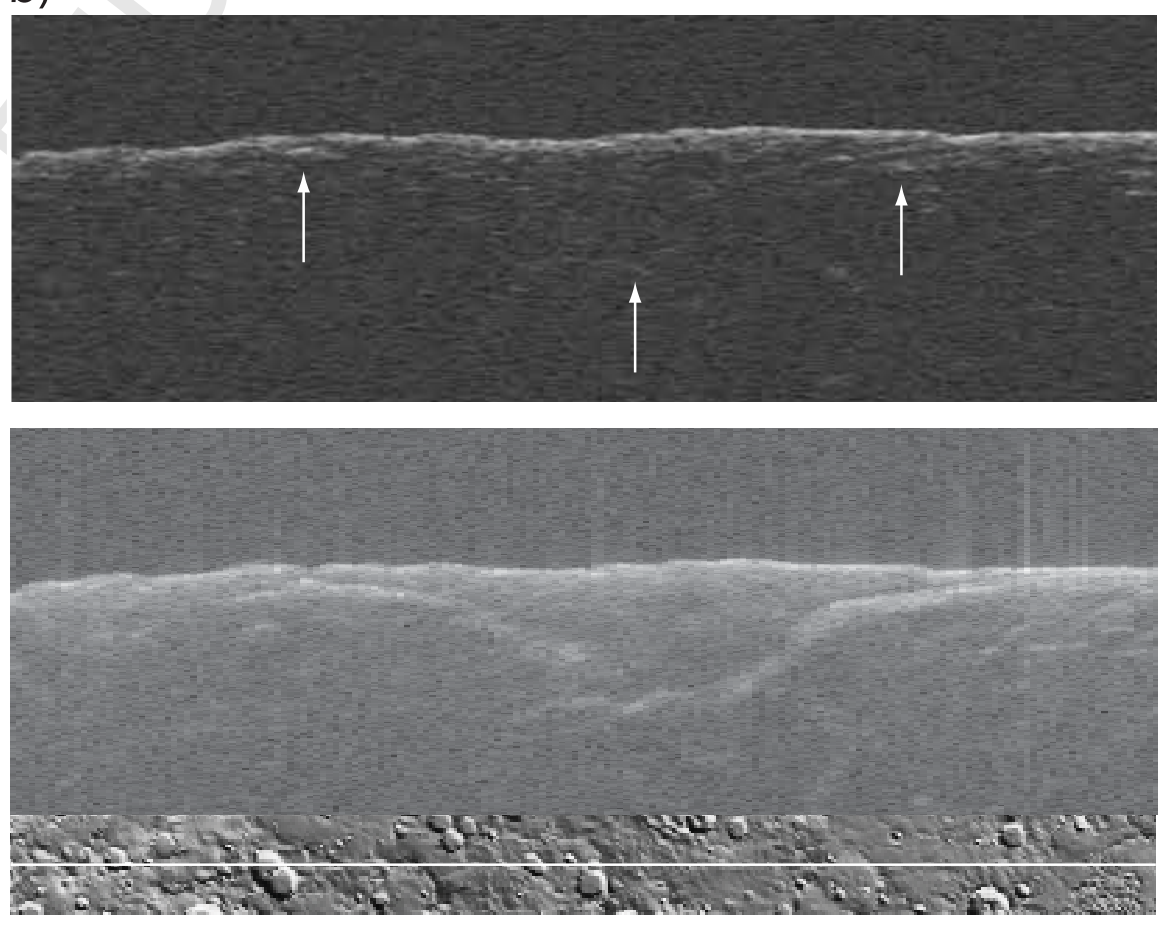


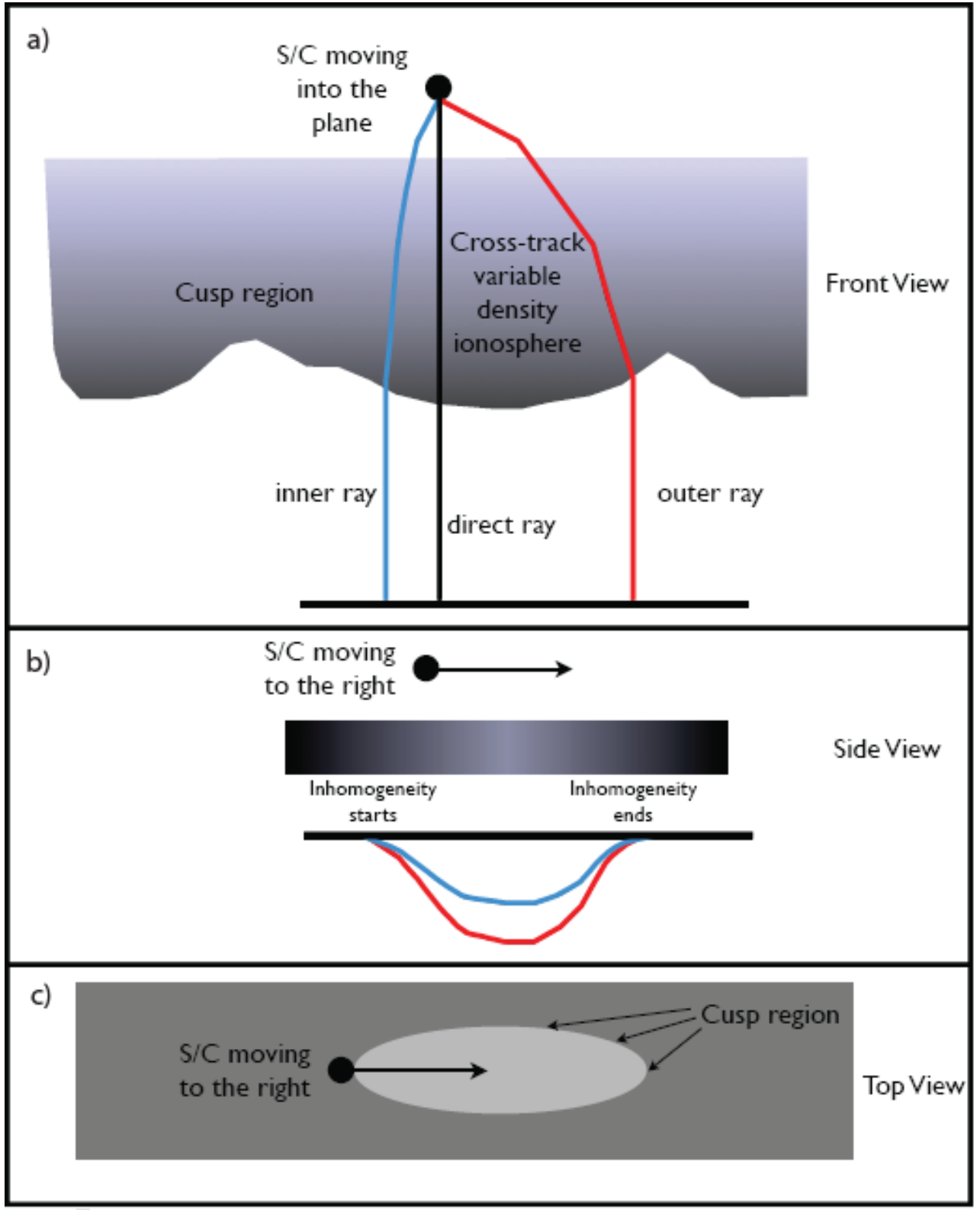


a) $15^{\circ} 52^{\circ} 22^{\prime \prime} \mathrm{s}$

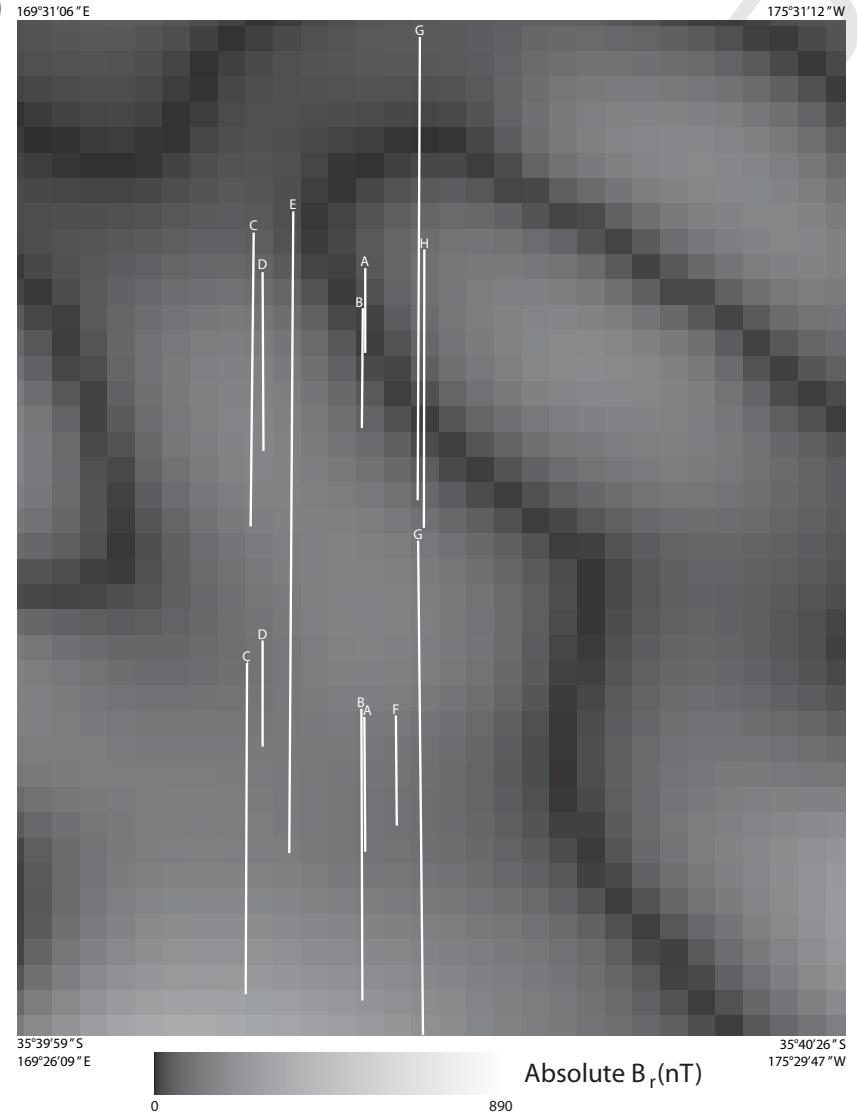

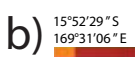

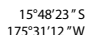

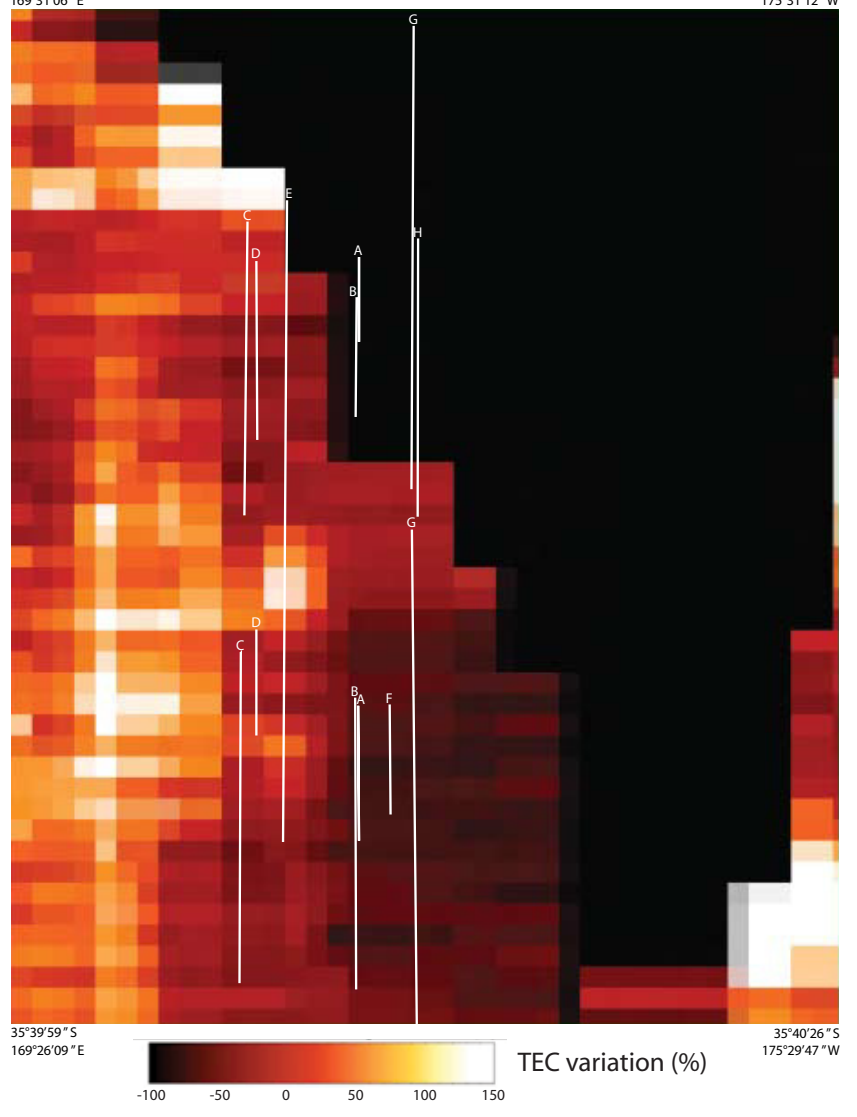




\section{ACCEPTED MANUSCRIPT}

\section{$1892(4 \mathrm{MHz})$}

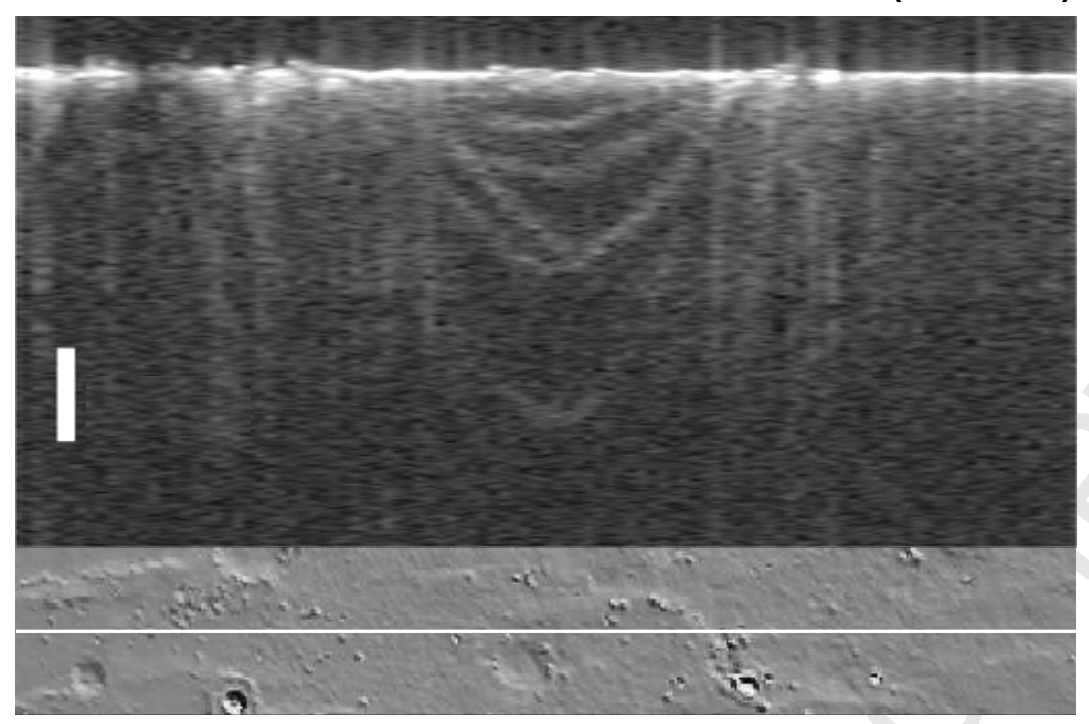

\section{3 (4 MHz)}

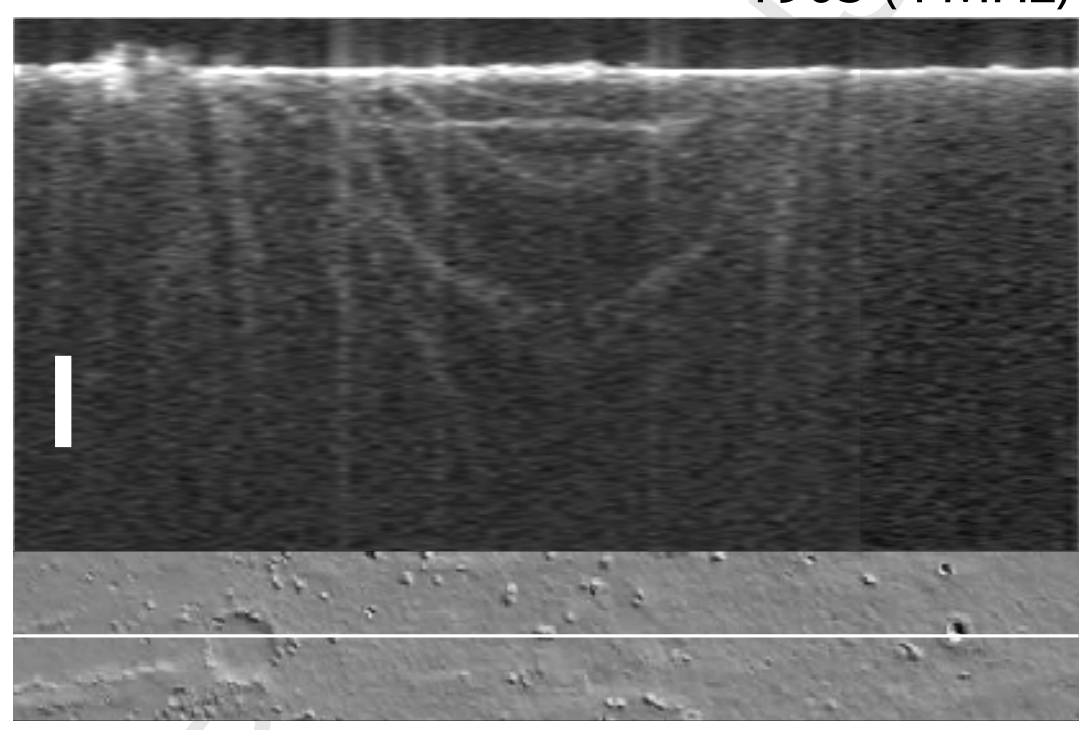

$3819(4 \mathrm{MHz})$

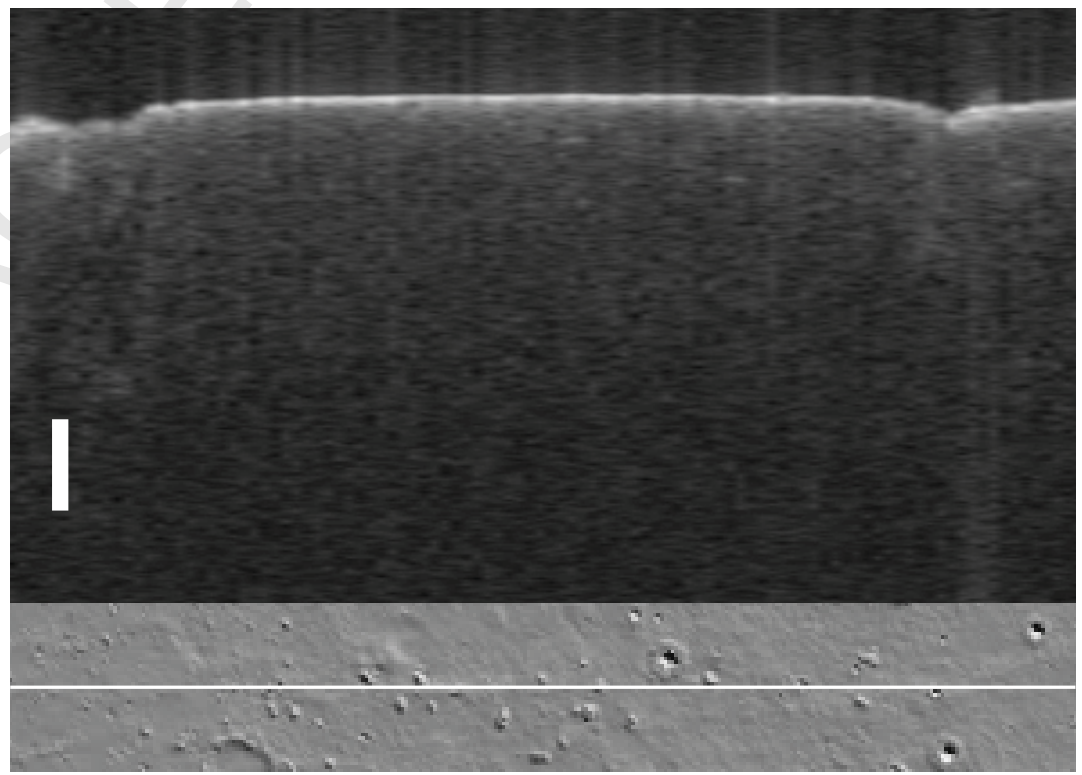

